Fig. 8.-Double invasion by a large and a small parasite. The large parasite is distinctly vacuolated. The pigment is collected into an oval mass at one side and the chromatin forms a crescent-shaped mass on the other.

Fig. 9.-Closely resembles fig. 8 .

Fig. I $\mathbf{i}$ - A large parasite showing a bundle of pigment rods and a single mass of rather loose-textured chromatin.

Fig. 12. - Large non-vacuolated parasite with two rounded masses of loose chromatin and a number of scattered pigment rods.

Fig. I 3.-Closely resembles fig. I 2, but the two masses of chromatin are more distinctly visible.

Fig. I4.-Large extra-corpuscular parasite.

Fig. 1 5.- Four large parasites in a single field. The uppermost resembles fig. I3, and the second and lowermost resembles fig. Ix. The remaining one, which is a little distorted, shows the first stage in the process of division. The chromatin is beginning to spread through the cytoplasm to form the chromatin "web."

Figs. I6-20.-Dividing parasites.

Figs. I 6 and 17 . - Show the chromatin spreading out in the form of interlacing filaments.

Fig. I8.- The process of condensation of the chromatin has started. Three small parasites are present in the corpuscle at the same time. (These are not quite in focus.)

Fig. I 9.-A parasite ready to fragment but still enclosed in a red corpuscle.

Fig. 20.-A parasite free from its corpuscle becoming fragmented.

Fig. 2 r.- The remains of a dividing parasite which has been ingested by a leucocyte.

Fig. 22.-Pigment granules within a leucocyte.

\title{
JOINT-ILL IN FOALS: ETIOLOGY AND SERUM TREATMENT.
}

By Sir John M'Fadyean, M.B., B.Sc., LL.D., and Capt. J. T. Edwards, M.R.C.V.S., B.Sc.

(From the Research Institute in Animal Pathology, Royal Veterinary College, London.)

\section{ETIOLOGY.}

IN a previous article in this Journal ${ }^{1}$ we described the results of a bacteriological examination of the diseased joints and other parts from thirty-seven foals that died from joint-ill in 1918 . During the current year we had sent to us similar parts from thirtyfive cases of the same kind, and, reserving the details with regard to some of them for future publication, we shall state here merely the diagnosis which appeared to be justified by the bacterioscopic and cultural examination of the affected joints in each of the cases.

I. In twenty-two of the cases the liquid in the diseased joints or pus from abscesses contained abundant streptococci, occurring in a state of purity in thirteen cases, and containing only a small proportion of other organisms, presumably accidental contaminations, in the remaining nine cases. 
2. In six cases coliform bacilli were present, either in a state or purity, or so greatly outnumbering other organisms present as to indicate that they were responsible for the lesions. In one of these the other organisms included a small number of streptococci.

3. The Bacillus nephritidis Meyer (or Bacterium viscosum equi Magnusson) was found in one case, accompanied by a few impurities.

4. In four cases organisms which could not with certainty be identified with any named species were present in a state of purity in the joints. The most interesting of these was a streptothrix, which was abundantly present, unmixed with any other organisms, in the diseased joint. A description of the morphological and cultural characters of this organism will be published later, but meanwhile, in view of the special interest attaching to the case, it has been thought well to insert the accompanying photograph of one of the very numerous colonies that were present in the joint contents.

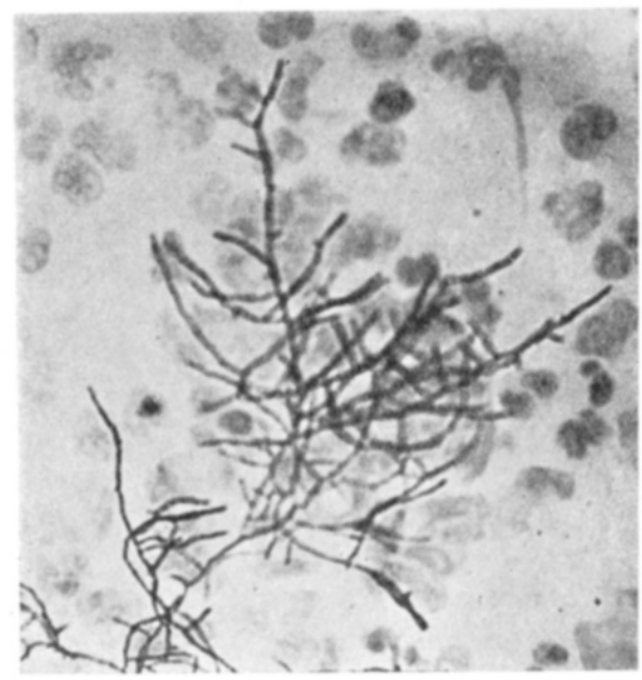

Micro-photograph of streptothrix in smear from liquid in joint $(\times 1000)$. Sce Case No. 13.

In two cases it was found impossible to come to any conclusion regarding the nature of the infection, but in neither of these were streptococci detected.

The number of cases examined in the two years was seventytwo, and in forty-five of these, or 62.5 per cent., streptococci appeared to be the cause of the disease, leaving 37.5 cases caused by other organisms.

This gives a much larger proportion of streptococcus infections than Magnusson ${ }^{1}$ found in 236 cases in Sweden (36.9 per cent.), ${ }^{2}$ but that author considered that in his series the proportion of streptococcus cases was depressed owing to the fact that fewer of the older foals were sent to him for examination, and, perhaps, also by a lowering of the mortality in cases of that kind by the anti-

I See p. 152 of this volume of the Journal.

2 This percentage includes $5 \cdot 1$ of cases caused by diplococci, which Magnusson classifies separately. 
streptococcus serum and vaccines with which the foals had been treated. It is probable that in our series the percentage of cases caused by the $\mathrm{B}$. nephritidis equi is too low, owing to the fact that in almost all our cases the joints or other parts were forwarded because the foals had died after treatment with serum. As a rule, the foals infected with that organism die sooner than those infected with streptococci, and a smaller proportion of them would, therefore, survive until a veterinary surgeon was called in and applied serum treatment.

Having regard to these facts, it would appear that the actual proportion of cases of joint-ill caused by streptococci is somewhere between Magnusson's figures and our own, or probably about 50 per cent.

\section{TREATMENT WITH ANTI-STREPTOCOCCUS SERUM.}

The large proportion of cases of streptococcus infections in the series of diseased joints sent to us for examination in 1918 caused us to abandon the opinion which we had previously formed as the result of our earlier observations, viz., that the $B$. abortivo-equinus was probably the commonest cause both of abortion in mares and joint-ill in foals in this country.

Recognition of the fact that probably not less than half of all the cases of joint-ill were caused by one organism, and that several different species of bacteria were responsible for the remainder, made it obvious that no striking success against the disease as a whole was to be expected from treatment with any kind of serum; but it was decided to concentrate efforts during the following foaling season against the chief offender, and we accordingly proceeded to prepare a specific anti-streptococcus serum, using for the purpose strains of streptococci isolated from the diseased joints of foals.

During the past season this serum, put up in doses of $25 \mathrm{cc}$, was supplied gratis to members of the profession who were willing to use it under certain conditions, which included the following:-

I. For curative purposes the serum was not to be used for foals that had been ill for more than seven days, or that had already been treated in any way. ${ }^{1}$

2. It was not to be used as a prophylactic except for foals born on premises in which a case of joint-ill had previously occurred during the season.

3. Whenever a dose of serum was used notice was to be sent to us immediately, giving the name of the owner of the foal, the date of its birth, the date of the onset of symptoms, the date on which serum was administered, and the number on the bottle (which indicated the number of the horse from which the serum was derived, and the date of the bleeding).

4. Members of the profession who used the serum were requested to keep notes of the cases, and from such records eventually to supply other information on special forms sent out for the purpose.

5. It was requested that an effort should be made to send us diseased joints or other parts from foals that died after treatment.

1 The reports received show that this request was ignored in a number of cases (see table: p. 233). 
We take this opportunity to express our great indebtedness to the members of the profession who in this way gave indispensable assistance in the investigation.

In all we received detailed reports regarding 253 cases of jointill treated with the serum, and we have thought it well to publish these in a condensed form at the end of this article, as, apart from the acutal termination in each case, they provide interesting information regarding the joints visibly affected, the progress of the illness, and the difficulty of founding a prognosis on the symptoms exhibited when a practitioner is first called in to treat a case.

In 130 of the cases the disease terminated fatally or the foal was destroyed on humane grounds when recovery appeared to be impossible. In the remaining 123 cases the foals were reported some months after treatment to have recovered, but in seven of them the recovery was then not complete.

The question that is now to be discussed is the interpretation, from the point of view of the value of the serum, of the fact that 130 out of 253 foals treated ( $5 \mathrm{I}^{\prime} 3$ per cent.) died.

In a previous report regarding a series of foals treated with serum specific against $B$. abortivo-equinus in 1917 , we recognised the difficulty of estimating the curative value (if any) of the serum, owing to the fact that the list did not include any control cases and there was not then available any trustworthy information to show what is the ordinary rate of mortality in joint-ill in foals, that is to say, the proportion of cases in which death might be expected to occur if the disease were allowed to run its natural course. Since no considerable number of diseased foals are left entirely untreated, it is not to be expected that figures bearing directly on this point will ever be provided, but it is fortunate that we are now in a position to provide evidence of an indirect character to show what the normal death rate of joint-ill in foals is.

Both in I9I 7 and 1918 we issued a serum from horses immunised with the $B$. abortivo-equinus, and collected information as to the results of the treatment in the same manner as during the last foaling season, when the anti-streptococcus serum was supplied.

The results obtained in I9I 7 have already been published. ${ }^{1}$ In that year 172 cases of joint-ill were treated, and 107 (or 64 percent.) of the foals died.

In I9I 8250 foals were treated with serum, and of these 127 (or 50 per cent.) died. In that year we requested the veterinary surgeons using the serum to send us a sample of blood in each case from the dam, and with very few exceptions this was carried out. These blood samples were all submitted to the agglutination test with the B. abortivo-equinus, and in every case with a result that contra-indicated infection of the mare with that organism.

It may therefore be assumed with much probability that the natural death rate in this 1918 series of cases. was not depressed by the cure of included cases of joint-ill caused by the bacillus of mare abortion, and therefore that the 50 per cent. of deaths in this series approximates to what would have been the death rate in the same foals if the disease had been allowed to run its natural course. This conclusion is justified because it cannot be supposed that the serum

1 "Journal of Comparative Pathology and Therapeutics," Vol. XXX., 1917, p. 321. 
used had any beneficial effect on the course of the cases of joint-ill caused by streptococci or other bacteria than the B. abortivoequinus.

If this view be adopted there appears to be no escape from the conclusion that the anti-streptococcus serum used during the present year had no influence on the death rate, which was actually $\mathrm{I}$ per cent. higher than in 1918.

It is true that in 1918 the death rate was lower than in 1917 , when the same kind of serum was used, and it might be suggested that the 64 per cent. of deaths in the latter year has as much right to be regarded as the natural mortality as the 50 per cent. in 1918 ; but, although we do not know of any published figures to support the view, the opinion held by many practitioners in this country is that joint-ill varies considerably in different years, both in its prevalence and in what may be called its virulence.

There are, however, besides the almost identical case mortality in the foals treated in I9I 8 and I9I9, other facts which appear to forbid the conclusion that the anti-streptococcus serum used in the latter year had any influence on the course of the disease.

The first of these is that the proportion of deaths remained almost the same whether the serum was given at a shorter or a longer interval after the onset of the illness. That is a fact made plain by the following table, and it need hardly be pointed out that it is strongly opposed to the view that the treatment had any effect in saving the lives of the foals, since all the accredited sera have the greater curative effect the sooner they are used after the beginning of the illness.

\begin{tabular}{|c|c|c|c|c|c|c|c|c|c|c|c|}
\hline $\begin{array}{c}\text { Day of Treatment } \\
\text { after } \\
\text { First Symptoms. }\end{array}$ & $\begin{array}{l}\vec{z} \\
\text { हे } \\
\text { हे } \\
\text { जे }\end{array}$ & हें & $\begin{array}{l}\dot{a} \\
\vec{\Xi} \\
N\end{array}$ & 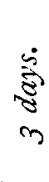 & $\stackrel{\dot{s}}{\vec{y}}$ & $\begin{array}{l}\text { है } \\
\text { है } \\
\text { in }\end{array}$ & $\begin{array}{l}\dot{c} \\
\dot{8} \\
0\end{array}$ & $\begin{array}{l}\dot{\hat{े}} \\
\text { हो } \\
1\end{array}$ & \begin{tabular}{l}
$\dot{5}$ \\
है \\
\multirow{2}{*}{+} \\
$\infty$ \\
$\infty$
\end{tabular} & 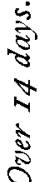 & $\frac{\dot{\Xi}}{\dot{s}}$ \\
\hline Deaths & 15 & 35 & 26 & I 6 & 8 & 4 & 3 & 6 & IO & 3 & I 26 \\
\hline Recoveries. & I 8 & 33 & 19 & 13 & I 4 & 3 & 3 & 9 & 5 & 3 & 120 \\
\hline Totals . & 33 & 68 & 45 & 29 & 22 & 7 & 6 & I 5 & I 5 & 6 & 246 \\
\hline
\end{tabular}

The second point is that the anti-streptococcus serum appeared to have no effect in reducing the proportion of cases in which streptococci were found in the joints of foals that had died after treatment. In this connection the experience of the previous season, when the other kind of serum was used, is again of value. In that season (I9I8), in a series of thirty-seven foals that died after treatment streptococci appeared to be the cause of the lesions in twentythree, leaving fourteen cases caused by other organisms.

During the past season the nature of the infection was determined in thirty-five foals, but three of these (two streptococci and one coliform bacilli) had not been treated with serum; among the 
remaining thirty-two there were twenty cases of streptococcus. infection. Neglecting fractions, the proportion of cases of streptococcus infection was thus identical in the two years, viz., 62 per cent.

It is true that both in 19 I 8 and I9I9 the nature of the infection was determined in only about one fourth of the foals that died, but the cases in which this was done were in no way selected, and there appears to be absolutely no reason for supposing that the result would have been substantially different if a bacteriological diagnosis. had been made in every case.

Having regard to all these facts, we feel obliged to draw the conclusion that the anti-streptococcus serum which we issued in 1919 . had no effect on the death rate. There remains the question whether the failure was inherent in the method, or due to the fact that the serum was inferior in quality. The following are the facts which suggest the correct answer, and indicate whether it is likely that better results may yet be obtained by using a serum of greater potency.

The serum issued was obtained from two horses (Nos. I2 and 13) whose immunisation had been in progress for between five and six months before the first bleeding, and for eight months before the last. The earlier inoculations were made with cultures killed by heat $\left(56^{\circ} \mathrm{C}\right.$.), and the later by young living cultures, these eventually reaching massive doses. At the outset both subcutaneous and intravenous inoculations were employed, but the former had to be abandoned owing to the severity of the local reactions. Intravenousinoculation was sometimes followed by very urgent symptoms, and it caused the death of one horse (No. 14), from which no serum had been issued. It was found to be impossible to hurry the process. of immunisation, owing to this danger, but towards the end the interval between the inoculations was reduced to three or four days.

The effect of each inoculation was ascertained by agglutination tests with streptococci, and bleeding for serum production was not practised until the agglutination titre (end point) had risen to $I$ in 2000. The highest titre reached was 1 in 5000 .

Each horse was immunised with a single strain (Horse 12 with Strain 52 and Horse 13 with Strain 47) obtained from a case of joint-ill, but comparative agglutination tests showed that the serum. from both had almost the same effect on other strains, including some isolated from human and bovine sources. The original intention was to pool the serum from the three horses, but when one of these died it was decided that it would be better to issue the serum from the surviving two separately, and to observe whether the results indicated any difference in their potency.

In a few cases at the end of the season mixed serum from the two. horses was used, and in others separate serum from the two horses was given to the foals on different dates.

The number of foals that received only serum from Horse 12 was. I30, and among these there were seventy-four deaths (or 57 per cent.). The number treated only with serum from Horse I 3 was IO3, and fifty-four of these (or 52 per cent.) died.

In the twenty cases in which streptococci were found in the 
lesions twelve had been treated with serum from Horse $\mathrm{I} 2$ and eight with serum from Horse I 3 .

Sixty-two of the foals were given two or more doses of serum, and of these twenty-six died, or 42 per cent. The higher proportion of recoveries here than among the foals that received only one dose of serum was probably due to the fact that practitioners were requested not to give a second dose sooner than a week after the first. With such an interval the majority of the most acute cases, owing to early death, would escape a second dose, and a larger proportion of those surviving would be mild cases tending to natural recovery.

It has already been mentioned that permission was given to use the anti-streptococcus serum for healthy foals born at any place where a case of joint-ill had already occurred during the season, but it would appear that in a considerable number of cases the serum was given to healthy foals irrespective of this condition. We have obtained reports regarding such prophylactic treatment in a number of cases, but the number is too small to make it worth while to tabulate the results. It ought, however, to be mentioned that the series of 253 cases which follows includes five cases in which the serum was used in this way (Cases 24, 32, I I3, 198, and 242), that in three of them the attack proved fatal although one or more doses of serum were given after the disease developed, and that two of these were proved to be cases of streptococcus infection. In two of the cases (Cases 24 and 32) it would perhaps be unfair to cite the result as evidence of failure of the prophylactic treatment, as the first symptoms were not shown until a month after the serum was injected.

It is, however, not unfair to observe that until convincing evidence of the curative effect of anti-streptococcus serum has been produced claims that it is valuable as a prophylactic ought to be regarded with a certain degree of mistrust. We have laid stress upon the fact that hitherto there has been no evidence on which one could form a confident estimate of the natural case mortality in joint-ill, and that without such an estimate the most fallacious conclusions can be drawn with regard to the effect of any form of treatment. At present the difficulty of judging the value of serum as a prophylactic is equally great, because it is impossible to say what should be regarded as the normal or usual incidence of joint-ill in foals. Information on this head that would have considerable value could be collected by some of the large breed societies in this and other countries, especially the Shire Horse Society and the Clydesdale Horse Society. Such information, in order to be of real value, would have to provide figures for several years, having regard to the prevalent opinion that the incidence of joint-ill in foals varies in different seasons. But even information collected in that way, and embracing large aggregate figures, would in most cases still leave great uncertainty in estimating the effect of serum as a prophylactic because of the erratic incidence of the disease in small studs in different years. It is undeniable that on certain farms a large proportion of the foals born during a period of two or more years may develop joint-ill, but that is not the rule, and the experience of any single year is therefore a most uncertain guide in estimating 
what will be the incidence of the disease in the next, or in deciding whether foals that remain healthy after a prophylactic injection of serum owe their escape to that treatment or not.

For these reasons we have not been able to attach any importance to reports in which an opinion highly favourable to the prophylactic value of the serum has been founded on the fact that a considerable number of foals, on nearly as many different premises, were given a dose of serum soon after birth and remained healthy.

Although there is no certainty with regard to the average incidence of the disease, the opinion may be hazarded that on an average not more than one foal in twenty born on farms in this country becomes the subject of joint-ill ; and, until that estimate has been shown to be erroneous, practitioners would be well advised to distrust the serum they have used if more than 5 per cent. of the foals are attacked.

In this connection it might be considered disrespectful if we did not refer to the views expressed by Magnusson in the valuable article which appeared in the preceding number of this Journal. It is there stated that reports were received of 500 foals which had been treated preventively with serum and vaccines, especially such as were dropped by mares which used to have joint-ill, and that only sixteen of these were attacked. The number that died is not given, but it is stated that the carcases of most of them were examined, and that no streptococci were found.

For the reasons already advanced, we should not consider sixteen cases in 500 foals as strong evidence of the value of the serum used as a prophylactic; and, with regard to the non-detection of streptococcus infection in any of them, it may be observed that, since only sixteen foals were attacked, the number post-mortemed can hardly have been sufficient to warrant the conclusion that streptococci were not responsible for any of the cases.

With regard to therapeutic treatment in which the foals were given both anti-streptococcus serum and vaccine, Magnusson admits that it apparently failed to prevent death in severe cases with highly developed lesions, but from the reports received he got the impression that it had a favourable effect in less severe cases which came under treatment early. In the absence of figures, however, showing the actual number of foals treated and the case mortality among them, we cannot accept this as convincing evidence that the results were any better than our own.

We also have received reports to the effect that the serum that we supplied had strikingly beneficial results in a considerable number of cases, but we now attach no importance to them as evidence of the value of the treatment, because such opinions were just as frequently expressed regarding the anti-mare-abortion serum issued in I9I 7 and I9I 8 as regarding the anti-streptococcus serum used last season. When any method of treatment fails to reduce the case mortality of a disease calculated on a large number of observations, exceptionally striking improvements or recoveries should not be attributed to the treatment unless other explanations are inadmissible. In the present case, since the facts already set forth compel us to conclude that anti-streptococcus serum did not reduce the case mortality calculated 
on over 250 cases, we regard what some of those who used it considered wonderful recoveries as due to natural causes, quite unconnected with the treatment.

In Magnusson's opinion foals over eight days old should be given large doses ( 100 to $200 \mathrm{cc}$.) of anti-streptococcus serum intravenously. In practice this would probably mean the majority of the foals which veterinary surgeons are called in to treat, and we certainly would not advise the adoption of that method in this country, until actual statistics embracing large numbers are published to prove that by it the case mortality of the disease can be reduced decidedly below the 50 per cent. which appears to be the normal. In view of the prices hitherto charged for the serum sold for the treatment of joint-ill, and the fact that no guarantee is furnished as to its potency, ${ }^{1}$ it would appear to be wiser in the meantime to discard serum treatment altogether.

It must be remembered that a correct diagnosis of the different infections included under the term joint-ill is at present impossible by ordinary clinical methods, and, therefore, that even if one were in possession of an efficient anti-streptococcus serum its general employment would mean an absolute waste in about 40 or 50 per cent. of the cases, viz., those that are caused by other bacteria than the streptococci. This is a difficulty that could not be avoided by the use of polyvalent serum purporting to be specific against the whole group of joint-ill organisms, for, in general, such a serum, unless given in very large doses, would be weak against every member of the group.

The main arguments that can be advanced against the use of serum in cases of joint-ill also apply to treatment by means of vaccines. It is true that, owing to the absence of any respectable body of evidence bearing on the question, it cannot be said that it has been proved to be useless; but, similarly, it has not been proved to be of any value. Even an efficient vaccine against streptococcus cases, like the corresponding serum, would be useless against the other forms of the disease, and to treat foals with vaccine prepared from cultures of all the joint-ill bacteria would scarcely be practicable.

Finally, at least against the use of vaccines with a therapeutic object, there is another reason, viz., that in many cases the foal would be dead before the expected effect of the vaccine could come into play.

As to the treatment of pregnant mares either by serum or vaccines, or of foals with serum from their dams, in order to prevent joint-ill, all that need be said is that these practices are based on opinions regarding the etiology of the disease that must now be considered erroneous, and that the claim that they are of any value has not been supported by the evidence necessary to prove that in a large number of unselected cases such treatment can reduce the mortality below the normal.

But, it may be asked, if both serum and vaccines must be regarded as of little or no value, how is joint-ill to be ccmbated? We

1 It may here be mentioned that such a serum, which was prepared by a well-known firm and issued in this country during the past season, was found to have no higher agglutination titre for streptococci isolated from cases of joint-ill than normal horse serum. 
believe the proper answer to that question to be that for the prevention of the disease attention should be diverted from serum and vaccines and concentrated afresh on measures calculated to safeguard the umbilical cord of the foal from infection immediately after birth and during the period of cicatrisation. When, in spite of such precautions, evidence of disease is discovered at the umbilicus, surgical measures must be employed to promote recovery from the local lesion before metastasis with resulting infection has occurred.

\section{LIST OF 253 CASES TREATED WITH ANTI-STREPTOCOCCUS SERUM.}

\section{Case No. I.}

Symptoms were first noticed on the twenty-first day after birth and serum was injected four days later. At this time the urachus had been discharging for fourteen days, and both hocks and one knee, shoulder, stifle, and elbow were swollen. Temperature $104^{\circ}$.

Result.-Complete recovery after about five weeks. On the day following treatment the temperature was $102^{\circ}$ and the following day ro2. $8^{\circ}$. The navel then appeared to be closed but there was little alteration in the joints. On the fourth day all the swellings appeared to be decreased and the temperature was ror $6^{\circ}$. After the tenth day there was slow improvement.

This was the only case of joint-ill on the premises during the season.

$$
\text { Case No. } 2 .
$$

Symptoms were first noticed thirteen days after birth and serum was injected the following day. Before treatment the navel was suppurating and the left knee was swollen. The temperature was high, respirations were hurried, and the foal was lame and showed a distressed appearance. The umbilicus was treated by probing and injecting hydrogen peroxide.

Result.-Recovery.

Two other cases of joint-ill (Nos. 4 and 7 ) and one doubtful case occurred on the same premises during the season.

\section{Case No. 3 .}

Symptoms were first noticed four days after birth and serum was injected two days later. Before treatment the navel was swollen and discharging, the right hock was inflamed, the temperature was high, respirations were hurried, and the foal showed a distressed appearance.

Result.-Death ten days after injection. After treatment there was no improvement except a slight temporary lowering of the temperature.

One of the hocks was sent to the College for examination and the case proved to be one of streptococcus infection.

No other case of joint-ill occurred on the premises.

\section{Case No. 4 .}

Symptoms were first noticed when the foal was a week old and serum was injected on the same day. The navel was discharging and the right hock was swollen. The foal was lame on that leg and had a high temperature. The navel was treated with injections of hydrogen peroxide.

Result.-Recovery.

This case occurred on the same premises as Nos. 2 and 7 . 
Case No. 5 .

Symptoms were first noticed when the foal was eighteen days old and serum was injected three days later. The navel was discharging, the left knee was swollen, and the foal was intensely lame on that limb. The temperature was high, the respirations were increased, and the foal had an anxious expression. The navel was treated by probing and injections of hydrogen peroxide.

Result.-Recovery. Progress was very slow and several doses of serum were injected. Improvement began after a clot of pus and coagulated blood had been washed out of the umbilicus.

No other case of joint-ill on the same premises during the season.

\section{Case No. 6.}

Symptoms were first shown when the foal was eighteen days old and serum was injected three days later. The left hock was much swollen and so painful that the foal was unable to rise without help. The temperature was high. Blood was said to have been aspirated from the distended hock.

Result.-Recovery. Progress was slow until after a channel had been made in the umbilicus.

No other cases on the premises this season.

\section{Case No. 7 .}

The first symptoms were noticed when the foal was thirteen days old and the serum was injected on the following day. The navel was discharging and the left knee and fore fetlock were affected. The temperature was high and the foal showed symptoms of paralysis of the hind quarters. The navel was treated by probing and syringed with hydrogen peroxide.

Result -Rapid and complete recovery.

Cases No. 2 and 4 occurred on the same premises.

Case No. 8.

Symptoms were first noticed when the foal was thirteen days old and serum was injected on the following day. The navel was discharging and the pus from it had a foetid odour. The right stifle and left knee were swollen and the foal was unable to get up without assistance. The temperature was high, respirations were hurried, and the expression was anxious. The navel was treated by probing and the injection of hydrogen peroxide.

Result.-Complete recovery.

The dam of this foal had for several seasons given birth to foals prematurely. ${ }^{1}$

$$
\text { Case No. } 9 \text {. }
$$

The symptoms were first noticed when the foal was six days old and serum was injected on the following day. One of the hocks was considerably swollen and fluctuating, and the foal was very weak. Temperature ro $4^{\circ}$. The foal had been born four weeks before its time.

Result.-Death four hours after the injection of the serum.

The diseased hock was sent for examination, which showed that the case was one of streptococcus infection.

This was the only case of joint-ill on the premises during the season.

\footnotetext{
1 In all the cases in which no reference is made to abortion it is to be understood that no mare on the premises aborted in 1919. 


\section{Case No. ro.}

Symptoms were first shown when the foal was five days old and serum was injected two days later. The navel was not discharging. One of the pastern joints was swollen and the foal was lame on that limb. Temperature $104^{\circ}$.

Result.-Death during the night following the injection of the serum.

The diseased limb was sent for examination, which showed that the case was one of pure streptococcus infection.

This was the only case on the same premises during the season.

\section{Case No. II.}

The foal was about five weeks old when the first symptoms were noticed and serum was injected two days later. At the time of treatment the navel was moist but not actually discharging, and one hock joint was affected. There were no other symptoms.

Result.-Progress after treatment was good and the case ended in complete. recovery.

This was the only case on the same premises during the season.

\section{Case No. I 2.}

Symptoms were first noticed thirteen days after birth and serum was injected on the following day. No particulars were furnished as to the foal's condition before treatment.

Result.-Death on the day on which the serum was injected.

The left hock of this foal was sent for examination, and on microscopic examination the fluid in the joint showed considerable numbers of short, slender bacilli, apparently in a state of purity. The exact nature of these bacilli was not determined.

\section{Case No. 13.}

Symptoms were first noticed when the foal was seventeen days old and a dose of serum was injected four days afterwards. A second dose was given eleven days later. At the time of treatment the left hock was affected and there was no other outward symptom.

Result.-Death two days after the second injection of serum. After treatment there was no improvement in the condition of the hock and the temperature was always about $104^{\circ}$. The joint was lanced eleven days after the first dose of serum was given.

This was the only case of joint ill on the same premises during the season.

After death the left hock was forwarded for examination, and bacteriological examination showed that the case was one of pure infection with a streptothrix (see p. 230).

$$
\text { Case No. I4. }
$$

Symptoms were first noticed when the foal was ten days old and serum was injected four days later. The navel was moist but not discharging. The right hock was inflamed and there was a swelling in the region of the withers. The foal was lame and had a depressed appearance.

Result.-Progress after treatment was good and the foal recovered, but slight swelling remained in the hock.

There was no other case of the disease on the premises during the season.

$$
\text { Case No. I5. }
$$

Symptoms were first noticed when the foal was twelve days old and serum was injected two days later. The general condition of the foal was 
good and it sucked well, but the urachus was pervious and the left hock was inflamed, causing lameness. Temperature $103^{\circ}$.

Result. - Recovery. After treatment the foal remained in the same condition for a week, but subsequently the swelling of the hock gradually declined. Three weeks after the injection the hock was still slightly enlarged, but there was then no lameness.

This was the only case of the disease on the premises this season.

Case No. I6.

Symptoms were first noticed when the foal was ten days old and serum was injected two days later. The left hock was inflamed and the foal was slightly lame on that limb. Temperature $103^{\circ}$. The navel was normal and the foal sucked well.

Result.-Death. Four days after the injection of serum the swelling of the hock was very pronounced and it had extended down to the fetlock. Temperature $102.5^{\circ}$. Four days later the swelling had declined, and the foal walked sound and appeared in good spirits. On the sixteenth day after the injection of the serum the foal had a severe attack of diarrhœea, and it died the same day. The hock at that time was normal in appearance.

This was the only case of the disease on the same premises during the season.

Case No. I 7.

Symptoms were first noticed when the foal was nine days old and serum was injected on the following day. The right knee and the right fetlock joint were then affected but the navel was normal. The foal had been born a week prematurely and it was weak and in poor condition.

Result. - Death twenty-four hours after the injection of the serum.

There were no other cases of joint-ill on the premises this season.

\section{Case No. 18.}

Symptoms were first shown when the foal was nineteen days old and serum was injected two days later. The right elbow and stifle joints were affected, but the navel was normal. The foal was breathing quickly and had much difficulty in standing. Temperature $105^{\circ}$.

Result.-Death within twenty-four hours of the injection of the serum.

This was the only case of the disease on the premises during this season.

\section{Case No. I9.}

Symptoms were first shown when the foal was eight days old and serum was injected six days later. The right stifle and hock joints were affected, causing very marked lameness. Temperature $1032^{\circ}$. The navel was not affected and the foal was in fair condition and sucked well.

Result.-After treatment the foal improved generally, and complete recovery took place.

This was the only case of the disease on the premises during the season.

Case No. 20.

Symptoms were first noticed when the foal was three days old and serum was injected on the same day. The left hock and fetlock joints were affected, and the foal was very weak, scouring, and showing symptoms of abdominal pain. It grunted while lying down and was only roused with difficulty. Temperature $104^{\circ}$. The navel was normal.

Result.-Death within twenty-four hours after the injection of the serum.

This was the only case of the disease on the premises this season. 


\section{Case No. $2 \mathrm{I}$.}

Symptoms were first shown when the foal was ten days old and a dose of serum was given four days later and repeated after other four days. The right stifle was the only joint affected, and the foal was lame on that limb. It sucked well and had a bright appearance. It lay down a good deal but was able to get up quite well. Navel normal.

Result.-Complete recovery. After the second injection the temperature fell but lameness persisted for some time. A blister was afterwards applied to the affected joint, and when seen after six months the foal was quite sound.

This was the only case of the disease on the premises during the season.

\section{Case No. 22.}

Symptoms were first shown when the foal was five days old and a dose of serum was given the same day and repeated seven days later. The right stifle was affected, but there was not much swelling and only slight lameness. Temperature $\mathrm{ro}_{4}^{\circ}$. The foal appeared bright and sucked. The navel was suppurating and the urachus was pervious.

Result.-Recovery. On the third day after the first injection of serum the right hock was found to be swollen, but gradual improvement took place after the second injection, the temperature dropping to normal and the joints slowly decreasing in size.

This was the only case of joint-ill on the premises this season.

\section{Case No. 23.}

Symptoms were first noticed when the foal was three days old and a dose of serum was injected on the following day and repeated six days later. The right stifle joint was swollen, hot, and painful, causing marked lameness. The navel was suppurating and the temperature was $104^{\circ}$. The foal's appearance was fairly bright and it sucked.

Result.-Death three days after the second injection of serum. The case never showed any improvement. The temperature remained at about $104^{\circ}$. The stifle burst spontaneously and the foal was never able to rise without help.

There was no other case of the disease on the same premises during the season, but there was one fatal case of joint-ill during the previous season. The present foal was born in a loose box and never went outside it. The navel was tied and disinfected at birth.

\section{Case No. 24.}

This foal was given a prophylactic dose of serum when twenty-four hours old. It was one month old when first treated, and symptoms had been noticed for the first time on the previous day. When first seen it was given a dose of serum and a second dose was given a week later. The right shoulder and elbow joints were enlarged, hot, and painful, causing marked lameness. The foal was dull in appearance, breathing rapidly, and had a temperature of $105^{\circ}$. The navel was quite normal.

Result.-Death three days after the second injection. Treatment was not followed by any improvement, and before death both hocks were attacked and the foal was unable to rise.

This was the only case of the disease on the premises during the season.

$$
\text { Case No. } 25 \text {. }
$$

Symptoms were first noticed when the foal was six days old and serum was injected on the following day and repeated seven days later. Both hocks and the right knee were much swollen, hot, and painful, causing marked 
lameness. The foal was dull, breathing rapidly, and unable to rise without help. The temperature was $104^{\circ}$, and the navel was suppurating and the urachus pervious.

Result.-Complete recovery. After treatment a steady improvement was shown. After the second injection the temperature became normal and the urachus closed. The left hock burst spontaneously and discharged for some time. At the time of birth the foal bled a good deal from the navel, which was tied by the owner with tape.

This was the only case of the disease on the premises during the season.

$$
\text { Case No. } 26 .
$$

Symptoms were first shown when the foal was four days old and serum was administered on the following day. The left hock and fetlock joints were swollen and hot, causing slight lameness. The navel was suppurating and the urachus pervious. The foal was dull in appearance, grunted, and suffered from diarrhoea with symptoms of colicky pains.

Result.-Death four days after the injection of serum. The foal gradually became worse after treatment, and abdominal pain persisted up to the time of death.

This was the only case of the disease on the premises during the season.

\section{Case No. 27.}

Symptoms were first shown when the foal was eight days old and serum was injected two days afterwards and repeated after seven days. The right hock was much enlarged, hot, and painful, causing marked lameness. The navel was suppurating. The foal sucked little and its temperature was $104^{\circ}$.

Result.-Death three days after the second injection of serum. The case never showed any improvement, the left hock and stifle joints became involved, and the foal was unable to rise or stand.

The foal had been born in a dirty box and the navel had been tied with string without the use of any antiseptic.

This was the only case on the premises during the season.

\section{Case No. 28.}

Symptoms were first shown when the foal was eleven days old and serum was injected three days later. The foal was very lame in the right hind limb, and the stifle joint was much enlarged, hot, and painful. The navel was suppurating and the urachus pervious. Temperature $105^{\circ}$. The foal was not sucking well.

Result.-The foal was unexpectedly found dead on the morning of the day following treatment.

There were no other cases of the disease on the premises during the season.

$$
\text { Case No. } 29 .
$$

Symptoms were first noticed when the foal was three days old and serum was injected the same day. The right hock and stifle joints were hot and painful but not much enlarged, and there was not much lameness. The navel was suppurating and the urachus pervious. Temperature $103^{\circ}$. The foal was dull and showed no inclination to suck.

Result.-Recovery. The temperature dropped to normal on the second day after the injection of serum, but the suppuration of the navel persisted for about a week.

During the season another foal was attacked with joint-ill and died. The present foal was the only one that the occupier of the farm had been able to rear in four years. He lost two in 1918 , and one in each of the preceding two years, all from joint-ill. 


\section{Case No. 30.}

Symptoms were first shown when the foal was fourteen days old and serum was injected the same day and repeated six days later. The foal was very lame in the right hind limb and the stifle joint was hot and painful but not much enlarged. The navel was suppurating, and the temperature was $\mathrm{r}_{4} 4^{\circ}$. The foal was dull and blowing, but it sucked well.

Result.-Recovery. The lameness persisted for about six weeks after the second injection and the foal then became quite sound, but three months later the same stifle joint was again found to have become enlarged, and lameness had returned. The swelling burst and discharged freely, but the foal again became quite sound.

This was the only case of the disease on the premises during the season.

Case No. $3^{\mathrm{I}}$.

Symptoms were first noticed when the foal was one week old and serum was injected the same day and repeated eleven days later. Both hocks were affected, and the foal was unable to rise without help. Temperature $103^{\circ}$. The navel was suppurating.

Result.-Death. Treatment was not followed by any improvement. Both hocks burst and discharged, and the foal finally died from exhaustion (date not stated).

Another fatal case of joint-ill occurred on the premises during the season.

\section{Case No. 32.}

This foal was given a preventive injection of serum when twenty-four hours old, but it developed symptoms of joint-ill a month later and it was afterwards 'given serum on three occasions, viz.: on the fourth, fourteenth, and twenty-first days. The right elbow joint and forearm were affected, causing intense lameness. Temperature ${ }^{\circ} 4^{\circ}$. The foal lay most of the time, did not suck, had a dull appearance, and was blowing. The navel appeared quite normal.

Result.-Recovery. Very little improvement was noticed until after the second curative injection of serum, after which the foal gradually improved. Recovery was complete after three months.

This was the only case of the disease on the premises during the season, but there were two cases in 1918 and a case of abortion in 1916.

\section{Case No. 33 .}

Symptoms were first noticed about three or four days after birth, but serum was not injected until the foal was about six weeks old. The navel had been discharging but had healed up at the time of the injection. The hip and stifle joints on one side were discharging pus, and the foal was very lame. After the injection of serum a seton was passed from the hip to the stifle joint so as to allow the pus to discharge.

Result.-Recovery. The foal appeared quite sound and well after four months.

No other case of the disease had occurred on the same premises during recent years.

\section{Case No. 34 .}

Symptoms were first shown when the foal was eight days old and serum was injected the same day. The navel was not quite dry and an antiseptic poultice was applied to it. The left hock was swollen and there was also a swelling on the chest wall. Temperature $103^{\circ}$.

Result.-Death thirteen days after the injection of serum. Two days after treatment was begun both hocks became affected, but the general condition of the foal appeared to be improved and the swelling gradually 
disappeared from the hocks. A week later the foal appeared ill, temperature $102.5^{\circ}$, and a dose of castor oil was given as the bowels were not acting properly. At this time the hocks and all the other joints seemed quiet normal. Two days later the right stifle was very much enlarged and painful and the foal was not looking well. On the following day the stifle was reduced in size but the disease had reappeared in the left hock, which was much swollen and caused intense pain. The foal died the same day, viz., thirteen days after the injection of serum. The veterinary surgeon expressed the conviction that the foal would have been saved if he had repeated the injection of serum.

The left hock of this foal was forwarded to the College and the bacteriological examination of the joint contents showed a pure streptococcus infection.

This was the only case of joint-ill on the premises during the season.

$$
\text { Case No. } 35 \text {. }
$$

Symptoms were first noticed when the foal was five days old and serum was injected on the following day and twice repeated, viz., after ten days and a month. The right stifle was the only joint visibly affected on the first day of treatment. The navel was discharging, although it had been tied at birth and painted with iodine. The foal was strong and in good condition.

Result.-Recovery. The left hock was attacked two days after the first injection of serum, the right knee two days after that, and the second knee four days later. Marked improvement was observed after each injection, and the veterinary surgeon expressed the opinion that the foal certainly owed its life to the repeated injections

This was the only case of joint-ill on the premises during the season.

$$
\text { Case No. } 3^{6 .}
$$

Symptoms were first noticed when the foal was seven days old and serum was injected two days later. The left stifle joint was affected and the foal was very stiff when moving, but the appetite was good. Temperature $105^{\circ}$. The navel was swollen and painful.

Result.-Complete recovery. The temperature became normal three days after the injection of serum, and in about ten days the lameness had disappeared.

No other foal was born on the premises during the season.

$$
\text { Case No. } 37 \text {. }
$$

Symptoms were first noticed when the foal was seven days old and serum was injected two days later. The left stifle and right hip joints were affected, but the navel appeared healthy.

Result.-Death after two months. There was no improvement after treatment.

There was no other case of the disease on the premises during the season.

$$
\text { Case No. } 3^{8 .}
$$

Symptoms were first noticed on the fifth day after birth and serum was injected two days later. The navel had not healed and it was dressed with antiseptics. The foal was very stiff, especially in the right hock, and it was unable to stand without assistance but would always suck well. Temperature $105^{\circ}$.

Result.-Death on the day after injection of serum.

The right hock and other parts of this foal were forwarded to the College, 
and bacteriological examination showed that the case was one of infection with the B. nephritidis.

There was no other case of the disease on the premises during the season.

$$
\text { Case No. } 39 .
$$

Symptoms were first noticed when the foal was a day old and serum was injected on the following day. The left knee was inflamed, and the foal was lame on that limb. Temperature $105^{\circ} 4^{\circ}$. The navel was moist.

Result.-Death twenty-four hours after the injection of serum.

The left knee was forwarded to the College, and examination of it showed a pure infection with coliform bacilli.

This was the only case of joint-ill on the premises during the season, but there was a case in 1918 .

$$
\text { Case No. } 40 .
$$

Symptoms were first shown when the foal was thirteen days old and serum was injected on the following day. The left knee and fetlock joints were affected and the navel was suppurating. The temperature was $105^{\circ}$ and the foal was dull in appearance.

Result.-Death two days after injection of serum.

There were no other cases of the disease on the premises during the season.

$$
\text { Case No. } 4 \mathrm{r} \text {. }
$$

Symptoms were first noticed when the foal was four days old and a dose of serum was given two days afterwards and repeated after twenty days. The left stifle and right knee joints were inflamed and the foal was very lame on these limbs. The navel was suppurating and the temperature had varied between $104^{\circ}$ and $105^{\circ}$.

Result.-Complete recovery. Some improvement was noticed after the first injection of serum, but later the condition remained stationary until the second injection was given, when progress became more rapid.

There was no other case of the disease on the premises during the season.

$$
\text { Case No. } 42 \text {. }
$$

Symptoms were first noticed when the foal was four days old and a dose of serum was given the same day and repeated seven days later. The left hip and stifle joints were affected, causing lameness. Temperature $105^{\circ}$. The navel was suppurating and the urachus was pervious. Respiration was hurried and the foal had a dull appearance and was not sucking.

Result.-Recovery. There was not much improvement until after the second injection of serum. The navel then dried up and the lameness diminished, but subsequently an abscess formed on the brisket and healed up after it was lanced. . Six months later the foal was sold for r $_{55}$ guineas.

The dam aborted two years previously, and there was one other case of joint-ill on the premises this season. Generally one or two cases had occurred on the place every year.

$$
\text { Case No. } 43 \text {. }
$$

This foal appeared to be ill at birth and symptoms of joint-ill were noticed on the following day. It was treated with serum a day later. Both hocks were affected and the temperature was $104.8^{\circ}$. The foal never sucked.

Result.-No improvement followed and death occurred two days after the injection of the serum.

- There was no other case of the disease on the premises during the season. 
Case No. 44 .

Symptoms were first noticed on the fourth day after birth and serum was injected on the following day. Both hocks were affected and the navel was supprurating.

Result.-No improvement. Death occurred five days after the injection of serum.

The dam had previously given birth to several healthy foals, but there had been cases of joint-ill every year on the farm. Pus sent from one of these for examination in 1918 showed a pure streptococcus infection.

\section{Case No. 45 .}

Symptoms were first shown when the foal was ten days old, and serum was injected the same day. The left stifle joint was affected and the navel was suppurating.

Result.-No improvement, and death on the third day after treatment.

The farm was said to have a bad reputation for joint-ill.

\section{Case No. 46.}

Symptoms were first noticed when the foal was fourteen days old and serum was injected on the following day. The right hock was the only joint affected and the navel appeared healthy.

Result.-The foal gradually got worse and it died on the fourth day after treatment.

There were no other cases of the disease on the premises during the season.

$$
\text { Case No. } 47 \text {. }
$$

Symptoms were first shown when the foal was thirteen days old and a dose of serum was given on the following day and repeated three days later. The left stifle and fetlock joints were affected. Temperature $105^{\circ} 4^{\circ}$ The navel was slightly moist.

Result.-No improvement, and death on the fourth day after the first injection of serum.

It was reported that the dam had been vaccinated previous to foaling with what was called the "Scottish Vaccine."

\section{Case No. 48.}

Symptoms were first shown when the foal was ten days old and a dose of serum was given on the second day afterwards and repeated a week later. Both stifles were affected, and an abscess had formed at the navel and been lanced before the injection of serum.

Result.-Complete recovery. There was no sign of improvement until after the second dose of serum.

This foal was born at a shooting lodge Io miles from any other place where horses were kept, and no other foal had been born there during the last twenty years at least.

\section{Case No. 49.}

Symptoms were first shown when the foal was fourteen days old and serum was injected three days later. The left stifle and hock joints were affected and the navel was suppurating.

Result.-The foal gradually got worse and it died about a week after the injection.

There was a case of abortion on the premises during the season. Alk the foals born on the place for a number of years had suppurating navels, but this was the first foal to be affected with joint-ill. 
Case No. 50.

Symptoms were first noticed when the foal was eighteen days old and a dose of serum was given three days afterwards and repeated after six days. The left stifle and hock joints were affected and the latter joint suppurated. The urachus was pervious. The foal was in very poor condition and had bedsores from lying down.

Result.-Death nineteen days after the second injection. The case never showed any improvement.

Another foal born on the same premises was reared without any trouble.

The left stifle joint of this foal was sent to the College and bacteriological examination showed that the case was one of streptococcus infection.

\section{Case No. $5 \mathrm{I}$.}

This foal was five weeks old when the first symptoms were noticed and it was treated with serum a week later. Both hock joints were affected, causing slight lameness, but the navel appeared healthy and the condition of the foal was fairly good. Improvement appeared to have set in before the serum was injected.

Result.-Recovery.

This was the only case of joint-ill on the premises this season.

\section{Case No. 52.}

Symptoms were first shown when the foal was nine days old and it was given a dose of serum on the following day. The knee and fetlock joints of one leg were swollen, causing lameness, and the temperature was $103^{\circ}$. The urachus was pervious.

Result.-After treatment the foal improved rapidly and eventually recovered.

This was the only case of the disease on the premises this season.

$$
\text { Case No. } 53 \text {. }
$$

The foal was fifteen days old when the first symptoms were shown and it was given a dose of serum two days afterwards. The right stifle was inflamed, causing lameness, and the navel was moist. Temperature $102^{\circ}$.

Result.-Gradual improvement occurred and the foal recovered.

This was the only case of joint-ill on the premises this season.

$$
\text { Case No. } 54 \text {. }
$$

The foal was sixteen days old when the first symptoms were noticed and it was given a dose of serum five days later. One elbow and one stifle joint were affected and a large abscess was discharging on one thigh. The navel was suppurating and the urachus pervious.

Result.-No improvement occurred after treatment and the foal died on the sixth day after the injection of serum.

This was the only case of the disease on the premises this season.

\section{Case No. 55 .}

Symptoms were not noticed until the foal was four weeks and one day old and it was treated with serum two days afterwards. One elbow joint was inflamed, causing lameness, and a suppurating swelling had formed over the elbow and had extended to the chest. The navel did not appear to be affected, but it had been dressed with iodine. The foal was in good condition.

Result.- No improvement, and the foal died thirty-seven days after the injection of serum. 
Case No. $5^{6 .}$

Symptoms were first noticed when the foal was seven days old and serum was injected on the following day. One elbow and one hip joint were affected, and an abscess had developed behind the hip joint. The navel had been discharging from birth. The foal was unable to get up and was very weak.

Result.-Incomplete recovery. Immediately after treatment the foal showed no improvement, but about three months later the lameness disappeared and the foal seemed to be putting on flesh.

This was the only case of the disease on the premises this season.

\section{Case No. 57 .}

The foal was one month old when it was first seen and it had been showing symptoms for two days. A dose of serum was injected. There was a large swelling over the stifle joint, causing marked lameness, and there was a slight discharge from the navel. Temperature $105^{\circ} 2^{\circ}$. General condition good.

Result.-Death twelve days after the injection of the serum. Four days after treatment the temperature was $1043^{\circ}$, the appetite was good, and the lameness was a little less severe. On the eighth day the temperature was ro $23^{\circ}$, the foal was still feeding well, and the discharge from the stifle and navel was reduced in amount. On the twelfth day a large abscess which had formed over the right stifle was opened. The foal was then in a much worse condition, and it died later during the day.

The left stifle joint of this foal was sent to the College but it was not received until six days after the foal's death. The exposed fleshy parts of the limb then had a marked odour of putrefaction. Cultures made from the interior of the joint yielded a rich growth of streptococcus mixed with a few colonies of other kinds.

This was the only case of the disease on the premises during the season.

\section{Case No. 58.}

Symptoms were first shown when the foal was four days old and serum was injected two days later. One hock and one stifle were affected, causing marked lameness, and a little fluid was escaping from the navel. The temperature was $105^{\circ}$ and the foal was unable to rise.

Result.-No improvement occurred and death took place two days after the injection of serum.

This was the only case of the disease on the farm during the season, but in 1918 the mare had a foal which was unable to suck and died.

\section{Case No. 59.}

Symptoms were first shown when the foal was six days old, and a dose of serum was given on the second day of illness and repeated after nine days. The left hock and stifle joints were inflamed, and the thigh of that limb was swollen. The navel appeared to be quite healthy, and the umbilical cord had been tied by the owner.

Result.-Destroyed fourteen days after the second injection. The foal became very much worse after treatment, and the swelling in the thigh became very extensive. It was unable to stand when destroyed.

The left hock and other parts of this foal were forwarded to the College and a pure culture of streptococci was obtained from the joint cavity.

Only one other foal was born on the farm during the season and it remained healthy. 
Case No. 6o.

The foal was a fortnight old when symptoms were first noticed and it was a month old when it was given a dose of serum. The navel was slightly swollen and suppurating, and the urachus was pervious. All the limbs at one time or another had shown signs of being affected. The foal had fever and loss of appetite, and it had failed to improve although kept under the best hygienic conditions.

Result.-Death seven days after the injection. No improvement was observed after treatment.

The right knee and left hock joints were sent to the College, and Gramnegative bacilli (B. coli) were cultivated in a state of purity from both joints.

'Two or three foals were bred on the premises each season, but there had been only one previous case of joint-ill during the last fifteen years.

\section{Case No. $6 \mathrm{I}$.}

The foal first showed symptoms when it was three days old and it was given a dose of serum six days later. The left hock was the only joint affected, but the navel was suppurating and the urachus pervious.

Result.-Death seven days after the injection. The foal appeared to be distinctly better on the day after the injection and the improvement was maintained for about six days.

This was the only case of the disease on the premises this season.

Case No. 62.

The foal was eleven days old when the first symptoms were noticed and it was given a dose of serum three days afterwards. The right stifle and hock joints were first affected, and afterwards the left hock became involved. The navel was suppurating slightly, and the foal showed general stiffness.

Result.-No improvement, and death nine days after the injection.

This was the only case of the disease on the premises this season.

\section{Case No. ${ }_{3}$.}

This foal was eight days old when the first symptoms were noticed and it was given a dose of serum four days later. The right knee and fetlock joints were affected, and the navel was suppurating. The foal appeared to be very ill.

Result. - The foal was destroyed when unable to rise two days after the injection.

The dam had previously given birth to three foals, all of which developed joint-ill. One of these died from joint-ill, but the other two survived and were sold at high prices.

\section{Case No. 64.}

Symptoms were first shown when the foal was five weeks old and a dose of serum was given seven days later and repeated after other four days. The hock, stifle, and hip joints on one side were affected, but the navel appeared healthy.

Result.-Death seven days after the second injection. There was some improvement at first, but four days after the first dose of serum the foal was worse, and the second dose did not produce any good effect.

This was the only foal born on the farm during the season.

\section{Case No. 65.}

The foal was eight days old when it first showed symptoms and it was given a dose of serum two days later. The right hock was affected and the navel was moist. Temperature $\mathrm{I}_{0} 4^{\circ}$ and respirations accelerated. 
Result.-Death. After treatment the foal seemed to be making satisfactory progress, but it was found dead sixteen days after the injection of serum. Death was said to have been due to rupture of an abscess internally.

The right hock joint and both kidneys of this foal were sent to the College, but the joint appeared healthy and no organisms could be cultivated from it. The kidneys also showed no gross lesions.

\section{Case No. 66.}

The first symptoms were shown when the foal was nineteen days old and serum was injected two days later. Both hocks and one stifle joint were affected, and the urachus was pervious. The foal was unable to rise without assistance.

Result.-Recovery. Progress at first was rather slow, but after a month there was marked improvement, and at the end of four months nothing remained but slight stiffness.

This was the only case of joint-ill on the premises during the season. The dam of the foal and two other mares were affected with fistulous withers.

$$
\text { Case No. } 67 .
$$

The foal was seven days old when the first symptoms were noticed and it was given a dose of serum on the following day. Both stifle joints were affected, the navel was suppurating, and the urachus was pervious. The foal lay a good deal and sucked irregularly.

Result.-Recovery. On the day after the injection of the serum the foal sucked well, and it continued to do so afterwards. The joints and the temperature had become normal after five days.

This was the only case of the disease on the premises this season.

$$
\text { Case No. } 68 .
$$

This foal was two months old when it was first affected, and it had been ill for a month when a dose of serum was injected. The left stifle and right knee joints appeared to be affected, and the foal was lame and showed fever.

Result.-Recovery. The temperature gradually fell and it remained normal after the sixth day. The lameness decreased and the foal walked sound at the end of three weeks, at which time it had also grown and improved in condition.

Case No. 69.

The foal was eleven weeks old when the first symptoms were noticed and a dose of serum was injected the same day. The right hock and stifle joints were very much enlarged, causing extreme lameness, and there was a slight discharge from the navel.

Result. - Incomplete recovery. After treatment the lameness steadily diminished, but it still persisted after two months, "the case remaining one of chronic arthritis."

This was the only case of the disease on the premises this season.

Case No. 70.

The foal was twenty-eight days old when it first showed symptoms and a dose of serum was given two days later. The left hock and stifle joints were affected, and the foal was very lame. The navel was swollen and discharging freely.

Result. - Recovery. After the injection of serum the foal steadily improved, but local treatment was continued for several days afterwards.

This was the only case of the disease on the premises this season. 


\section{Case No. 7 I.}

The foal was seven days old when it first showed symptoms and a dose of serum was given on the following day and repeated eleven days later. The left hock was inflamed, causing lameness, and the navel was discharging. slightly. The temperature was a little above normal.

Result.-Recovery. After treatment progress was uninterrupted.

There was no other case of the disease on the premises during the season.

Case No. 72.

The foal was fourteen days old when the first symptoms were noticed, and a dose of serum was given the same day. The left hock was affected, causing slight lameness, and there was a slight discharge from the navel.

Result.-Uninterrupted recovery.

There was another case on the same premises during the season.

\section{Case No. 73 .}

The foal was eight weeks old when it was first treated with serum, and it had then been showing symptoms for three days. The left hock was. affected, and there was an extensive swelling over the left stifle and another on the right side of the chest. The navel was slightly swollen and discharging.

Result.-Death (date not reported). There was no improvement at any time, and the hock suppurated ten days after the commencement of treatment.

This was the the only case of the disease on the premises this season.

\section{Case No. 74.}

The foal was thirteen days old when it was first seen to be ill and it was given a dose of serum on the following day. The right hock was slightly enlarged and the navel was discharging.

Result.-No improvement, and death four days after the injection of serum.

Two other foals born on the premises escaped infection.

$$
\text { Case No. } 75 \text {. }
$$

The foal was eight days old when it first showed symptoms and a dose of serum was injected six days later. Both knees and hocks and the left stifle were affected, and the navel was suppurating. Temperature $104^{\circ}$. The foal lost condition, but the appetite was retained.

Result.-No improvement, and death eight days after the injection of the serum.

The right knee of the foal was sent to the College, and preparations made from the fluid in the radio-carpal joint showed a considerablenumber of Gram-negative, slender bacilli, varying in length from $\mathrm{I}^{\cdot} 5$ to. 6 microns. The exact species of these organisms was not determined.

This was the only case of joint-ill on the premises this season.

Case No. 76.

The foal was twelve days old when the first symptoms were noticed: and serum was injected two days later. The left shoulder was the onlyjoint affected, but the navel was moist. The foal was disinclined to move, and the temperature was above normal.

Result.- No improvement, and death three days after the injection of the: serum.

There was no other case of the disease on the premises this season. 
Case No. 77 .

The foal was three weeks old when symptoms were first noticed and it was given a dose of serum on the following day. The left knee and hock joints were affected, and the foal was dull and showed diminished appetite. The temperature was $103.5^{\prime \prime}$, and the navel was apparently healthy.

Result.-Death five days after the injection of the serum. After treatment the left fore fetlock was attacked and burst, and the foal rapidly became worse, although the temperature had fallen to $102^{\circ}$.

The left fetlock was forwarded to the College, and bacteriological examination showed that the case was one of streptococcus infection.

There was no other case of the disease on the premises this season.

\section{Case No. 78.}

The foal was seventeen days old when its was first attacked and serum was injected four days later. The left hock was the only joint affected, and it was very much inflamed. The navel was normal.

Result.-Recovery. After treatment the swelling of the left hock slowly decreased, but a few days later the opposite hock and stifle joints became swollen. All three joints showed intermittent swelling for about two months, but finally the foal made a good recovery.

This was the only case of the disease on the premises this season.

\section{Case No. 79 .}

The foal was twenty days old when first symptoms were shown and serum was injected on the following day. The left hock was very much enlarged, and the temperature was $104^{\circ} 6^{\circ}$. The navel appeared normal.

Result.--Recovery. On the day following treatment the temperature was ro $4^{\circ}$, and the swelling of the joint was softer. Three days later the temperature was $101^{\circ} 5^{\circ}$, and the swelling had burst, but the foal appeared much brighter. The joint swelling decreased and the wound soon healed up, but it burst again and discharged freely. Subsequently recovery was uninterrupted.

This was the only case on the premises during the season.

Case No. 80.

The foal was eighteen days old when it was first attacked and a dose of serum was given three days later. Both hock joints were affected, but the navel appeared normal.

Result.-Recovery. The swelling of the left hock disappeared after about ten days, but that in the right hock remained and caused lameness for about: a month.

Another foal had been attacked on the same premises during the season and had died.

\section{Case No. $8 \mathrm{I}$.}

The foal was first noticed to be ill when it was three weeks old and it was given a dose of serum a week later. The right elbow joint was suppurating, the temperature was high, and the foal was unable to rise. The navel was discharging, although it had been disinfected at birth.

Result. - Death on the day following the injection.

The right elbow and other parts of this foal were forwarded to the College, and bacteriological examination showed that the case was one of streptococcus infection. 
Case No. 82.

The foal was a week old when it was first attacked and serum was injected seven days later. The foal was intensely lame in the right hind limb, and the stifle and hock joints on that side were affected. Temperature $103^{\circ} 2^{\circ}$. The navel was apparently normal, and the foal was in fair general condition and sucked well.

Result.-After treatment there was gradual improvement, which ended in complete recovery.

This was the only case of the disease on the premises this season.

$$
\text { Case No. } 83 \text {. }
$$

The foal was attacked when eleven days old and a dose of serum was given three days afterwards and repeated after two and five days. The left fore fetlock and left stifle and hock joints were affected. The temperature was $103^{\circ}$, and the urachus was pervious.

Result.-After treatment the foal made an uninterupted recovery.

This was the only case of the disease on the premises during the season.

\section{Case No. 84.}

The foal was fourteen days old when the first symptoms were noticed and it was given a dose of serum two days later. One of the stifle joints was very much swollen, causing marked lameness; temperature $103^{\circ}$. The navel was apparently normal, but the foal was dull and not sucking.

Result.-Recovery, which was practically complete in about nine days.

This was the only case of the disease on the premises this season.

$$
\text { Case No. } 85 \text {. }
$$

The foal was about five weeks old when it was first treated with serum and it had then been showing symptoms for five days. The right hock and the left stifle joints were affected; temperature $104^{\circ}$, and breathing accelerated. The foal was very thin and extremely lame, but the navel appeared normal.

Result.-Recovery. Two days after treatment the swelling of the hock was much less tense, and the lameness was not so marked. Seven days later the hock was normal, and the swelling in the stifle had decreased. Subsequently the foal made an uninterrupted recovery.

This was the only case of joint-ill on the premises this season.

\section{Case No. 86.}

Symptoms were first noticed when the foal was twelve days old and it was given a dose of serum two days later. The left hock and both knees were affected, and the navel was slightly swollen and suppurating.

Result.-Death on the day following treatment.

The right hock and the kidneys of this foal were forwarded to the College, and the examination showed that the case was one of streptococcus infection.

$$
\text { Case No. 87. }
$$

The foal was thirteen days old when the first symptoms were noticed and it was given a dose of serum on the following day. Both stifle joints were slightly enlarged, the temperature was $104.5^{\circ}$, and respiration and pulse were accelerated. The foal sucked irregularly, was stiff, and lay down a good deal. The navel was apparently normal.

Result.-Recovery. On the third day after treatment the foal seemed quite lively, the stiffness had disappeared, and the temperature was $101^{\circ}$, 
but the stifle joint still remained swollen. It was about three months before the joints became normal.

This was the only case of joint-ill on the farm during the season, but the same mare's foal died from joint-ill in I9r8.

\section{Case No. 88.}

The foal was eleven days old when the first symptoms were noticed and a dose of serum was given three days later. Both knees were affected, and the right hind leg was swollen from the stifle to the hock; temperature $104^{\circ}$. The navel was suppurating, but the foal was in good spirits and sucking.

Result - No improvement, and death (date not reported).

This was the only case of joint-ill on the premises this season.

\section{Case No. 89.}

This foal was twenty days old when the first symptoms were noticed and it was given a dose of serum on the following day. The knee and hock joints were affected, and the foal was unable to rise without assistance. The navel was suppurating.

Result.-The foal gradually got worse, and died (date not reported).

This was the only case of joint-ill on the premises this season.

\section{Case No. 90.}

Symptoms were shown on the fourth day after birth and a dose of serum was given on the following day. The left hock was much swollen and the foal was stiff in all its limbs; temperature $104^{\circ}$. The navel was swollen and suppurating.

Result.-No improvement, and death "three or four days" after treatment.

There were no other cases of the disease on the premises this season.

$$
\text { Case No. } 91 \text {. }
$$

The foal was twenty days old when the first symptoms were noticed and it was given a dose of serum on the following day. The right hock was very much swollen, causing great lameness; temperature $104^{\circ}$. The navel appeared to be normal, and there were no other symptoms.

Result.-Death. After treatment the lameness diminished considerably, and the swelling of the hock was reduced for a few days, but the foal then had a relapse and eventually died (exact date not reported).

This and the following case occurred on the same premises, and were the only cases of joint-ill during the season.

$$
\text { Case No. } 9^{2} \text {. }
$$

The foal was six days old when symptoms were first noticed and a dose of serum was given on the following day. The right hock was swollen, causing much lameness, and the temperature was $104^{\circ}$. The navel was suppurating.

Result.-No improvement, and death "after a few days" (exact date not reported).

\section{Case No. 93 .}

The foal was twelve days old when the first symptoms were noticed and it was given a dose of serum on the following day. Both knee and hock joints were affected, and the foal was very lame, although the joints were not much swollen. The navel was suppurating, and the temperature was $103^{\circ}$. The foal had to be assisted to rise. 
Result.-Recovery. After treatment the foal remained stiff and lame for about a week, but it then began to improve and had quite recovered after a fortnight.

This was the only case of the disease on the premises this season.

\section{Case No. 94 .}

The foal was five days old when it was first noticed to be ill and it was treated with serum two days later. Both knee and hock joints were attacked, and the temperature was $1044^{\circ}$. The navel was suppurating, and the foal was unable to get up without assistance.

Result.-Death "two or three days" after the injection of serum. There was no improvement after treatment.

There were no other cases of the disease on the premises during the season.

\section{Case No. 95.}

The foal's age was three weeks and four days when it was first noticed to be ill and a dose of serum was given seven days later and repeated after other four days. One elbow joint was affected, causing marked lameness. The foal's condition was poor, and it had to be assisted to its feet in order to suck; temperature $105^{\circ}$. The navel was swollen and discharging a little.

Result.-Recovery. One hock joint became affected three days after the first injection, and it was a long time before recovery was complete.

There were no other cases of joint-ill on the premises during the season.

\section{Case No. 96 .}

The foal was five days old when it was first noticed to be ill and it was given a dose of serum on the following day. One elbow was slightly swollen and very painful, and the foal was unable to rise without assistance.

Result.-Destroyed sixteen days after the injection. There was no improvement; the elbow joint was opened on the fourteenth day after the injection, and two days later one of the stifle joints became affected, and the case was regarded as hopeless.

\section{Case No. 97.}

The foal was two days old when it was first noticed to be affected and a dose of serum was given the same day. The left fetlock was the only joint affected, but the foal was very weak.

Result.-Death. The joint swelling gradually diminished, but the foal rapidly became weaker and died two days after the injection of serum.

Two previous foals out of the same mare died from joint-ill.

$$
\text { Case No. } 98 \text {. }
$$

The foal was eighteen days old when it as first noticed to be ill and it was given a dose of serum three days later. The shoulder, knee, and hock joints were affected, and the navel was swollen and suppurating. The temperature varied from $102^{\circ}$ to $105^{\circ}$.

Result.-Recovery after about three months. After treatment the foal became worse, and, as it had to be lifted up for about three weeks to suck, the owner wished to have it destroyed.

This was the only case of the disease on the premises this season.

$$
\text { Case No. } 99 .
$$

The foal was about five weeks old when it was given a dose of serum and it had then been ill for four days. The right shoulder and hock joints were 
slightly affected and the navel was slightly inflamed. There were no other symptoms.

Result.-Partial recovery. The swelling of the joints disappeared, but the foal remained lame in the shoulder three months after treatment.

Case No. 100

The foal was seven days old when it was first noticed to be ill and it was treated with serum two days later. The left knee was the only joint affected, but the navel was suppurating and the urachus pervious. The foal was in low condition.

Result.--The foal made a gradual and uninterrupted recovery.

Eight other foals born on the same premises during the season remained healthy, but cases of joint-ill had occurred at the same place in previous seasons.

$$
\text { Case No. IoI. }
$$

This foal was eight days old when it was first attacked and a dose of serum was given on the following day. The left forearm was affected, and the foal showed acute general symptoms. The navel was suppurating and the urachus pervious.

Result.-Destroyed thirty-five days after the injection of serum. After treatment there was an appreciable improvement for nine days, but the foal then had a relapse, and a number of abscesses formed at different times in connection with the joints and quarters. The foal was destroyed as the case appeared to be hopeless.

Three other foals born on the premises this season remained healthy.

Case No. 102.

This foal was seven days old when it was first seen to be affected, and it was given a dose of serum two days later. The left hock and stifle joints were affected, and the navel was suppurating and the urachus pervious.

Result--The foal made a slow but uninterrupted recovery.

There were no other cases of joint-ill on the premises, but one mare aborted twins. Three other mares foaled successfully during the season.

$$
\text { Case No. ro3. }
$$

The foal was eleven days old when the first symptoms were noticed and a dose of serum was given on the same day. The left hind fetlock was the only joint affected, but the navel was suppurating and the urachus pervious.

Result.-Recovery. Progress was slow but uninterrupted. There was still some lameness after three months, but that had disappeared after six months.

There were no other cases of joint-ill on the premises during the season. One mare aborted and three others foaled successfully.

$$
\text { Case No. } 104 .
$$

The foal was noticed to be affected twelve hours after it was born, and a dose of serum was given the same day. Both hind fetlocks were affected and the urachus was pervious. The foal appeared very ill.

Result.-Death on the following day.

Two other foals born on the premises remained healthy. No case of joint-ill had occurred on the place for seven years.

$$
\text { Case No. } 105 .
$$

The foal was a week old when the first symptoms were noticed and it was given a dose of serum seven days later. The stifle, knee, and elbow joints 
were affected, and the foal was dull and could not get up without assistance. The navel appeared to be normal.

Result.-Recovery. The foal remained lame for some weeks, but eventually all the symptoms disappeared rather suddenly.

This was the only case of joint-ill on the premises this season.

\section{Case No. I06.}

The foal was seven days old when the first symptoms were noticed and it was given a dose of serum three days later. The right hock was the only joint affected, but the foal had a febrile temperature and it was unable to stand for any length of time on its feet. The navel had been dressed soon after birth, and at that time the foal had to be held up to suck. The navel was suppurating and the urachus pervious.

Result.-Death after a month.

At first there was some improvement, but the left hock appeared to give way under the strain although the right hock had recovered its normal size. Eventually the foal developed bedsores and other lesions.

There were no other cases of joint-ill on the premises during the season.

\section{Case No. 107.}

The foal was three days old when it was first noticed to be affected and it was given a dose of serum three days later. The left stifle joint was affected and the urachus pervious. The foal was disinclined to suck.

Result.--Slow but steady improvement, and complete recovery in five weeks.

There was no other case of the disease on the premises during the season.

$$
\text { Case No. } 108 \text {. }
$$

The foal was eight days old when it was first noticed to be affected and a dose of serum was given four days later. The left knee and stifle joints were affected, and the foal showed general symptorns. The navel was suppurating and the urachus pervious.

Result. - The foal made an uninterrupted recovery.

There were no other cases of the disease on the premises during the season.

\section{Case No. rog.}

The foal was five days old when it was first noticed to be affected and it was treated with serum three days later. The left stifle and hock joints were affected, and the foal was disinclined to rise and suck: temperature $104^{\circ}$. When up it was unable to stand owing to pain in the fore legs. The navel was suppurating and the urachus pervious.

Result.-Destroyed. At the cime of treatment a ligature was applied to the umbilical cord. Sloughing occurred in three days and another ligature was then applied. The left hind limb eventually recovered, but the foal was unable to stand, and it had to be destroyed (exact date not reported) on account of the condition of the fore limbs.

There had been a previous fatal case of joint-ill on the same farm during the season.

\section{Case No. I Io.}

The foal was seven days old when it was first noticed to be ill and it was given a dose of serum seven days later. Both hocks, stifles, knees, and fore fetlocks were affected. The navel appeared to be healthy.

Result.-Recovery. For a fortnight after treatment the foal was unable to rise without assistance, but afterwards it made an uninterrupted recovery.

The foal was at pasture all the time, and there were no other cases of joint-ill on the farm during the season. 
Case No. II I.

The foal was six days old when it was first seen to be ill and a dose of serum was given on the following day. The animal was very lame in the left hock joint. The navel appeared normal.

Result.-The foal gradually became worse and died three days after the injection.

There were no other cases of the disease on the premises during the season.

\section{Case No. I I 2.}

The foal was twelve days old when an injection of serum was given and the navel had then been suppurating for two days. No joints were then affected, but the temperature was $105^{\circ} 4^{\circ}$, and the foal was showing constitutional symptoms. A second dose of serum was given (date not stated).

Result.-Death about five or six days after the first dose of serum. Two days after the first injection the hock, stifle, fetlock, and knee joints became affected. The foal's left bock was forwarded to the College, where the examination showed that the case was one of pure streptococcus infection.

\section{Case No. ${ }^{11} 3$.}

This foal was given a preventive dose of serum when it was six days old and it was ten days old when the first symptoms were noticed and another dose of serum was given. The right hock was the only joint affected; temperature $\mathrm{IO}_{3} 2^{\circ}$. The foal showed loss of appetite, had a staring coat, and was disinclined to get up. The navel was swollen and suppurating.

Result.-Partial recovery. Progress was slow and for some time the foal had to be assisted to rise. Three months afterwards the hock was still enlarged but the foal was going sound.

There were no other cases of joint-ill on the place during the season, but the same mare's foal died from joint-ill in r 918.

\section{Case No. II 4 .}

The foal was four days old when it was first attacked and a dose of serum was given three days afterwards. Three other doses of serum were given, viz., on the seventh, fourteenth, and twenty-second days afterwards. When first treated the left stifle, hock, and fore fetlock joints were affected; temperature $1024^{\circ}$. The navel was slightly swollen and suppurating.

Result.-Death one month after the second dose of serum. There was no improvement under treatment. At the time of the second injection the temperature was $104^{\circ}$ and it was still $104^{\circ}$ when the fourth injection was given. At that time the swelling of the joints had disappeared, but the back was arched and the hind limbs were stiff.

This was the only case of joint-ill on the premises this season.

\section{Case No. II 5 .}

The foal was five weeks and four days old when it was first seen to be ill and it was given a dose of serum three days afterwards. The left stifle and hock and the right knee and fore fetlock were all affected, and the temperature was $1034^{\circ}$. The navel appeared to be healthy.

Result.-Death on the third day after the injection of serum. No improvement was observed, and the right fore fetlock burst on the day following treatment.

There were no other cases of the disease on the premises during the season. 
Case No. I 16.

The foal was twelve days old when it was first attacked and a dose of serum was given seven days later and repeated after other three days. The first symptom was discharge from the navel, and two days later the left hock became swollen and painful. Temperature varied from $103^{\circ}$ to $105^{\circ}$.

Result.-Death. There was no improvement; the left shoulder became affected, and the swelling in the hind leg became larger and had to be opened. Death occurred about seven days after the second injection.

The left shoulder of the foal was forwarded to the College and the examination showed that the case was one of streptococcus infection.

\section{Case $N o$. I I 7 .}

The foal was thirty-one days old when it was first seen to be affected and a dose of serum was given four days later. The left hip joint was affected and the foal was very lame; temperature i o2. $8^{\circ}$. The navel was normal.

Result.-Death thirteen days after the injection of the serum. The foal gradually got worse, diarrhœea set in, and a large abscess formed at the hip.

Several cases of joint-ill had occurred on this farm in previous years and they nearly all recovered under medicinal treatment (nature not stated).

\section{Case No. I I 8 .}

This foal was six days old when the first symptoms were shown and a dose of serum was given the following day. The left hock joint was swollen and the foal was distinctly lame on that $\operatorname{limb}$; temperature $102^{\circ}$. The navel was suppurating and the foal had a dull appearance.

Result.-No improvement, and death eight days after the injection of serum.

There were no other cases of the disease on the premises this season.

\section{Case No. I 19 .}

This foal was eighteen days old when the first symptoms were noticed and it was given a dose of serum three days later. 'The right stifle was enlarged and the foal was very lame in that limb; temperature $103^{\circ} 6^{\circ}$. The navel was dry and nearly healed up.

Result.-Complete recovery.

This was the only case of joint-ill on the premises this season.

\section{Case No. I 20.}

The foal was one month old when first treated and it was said to have shown symptoms for about three weeks previously. The only joint affected was the left stifle and the foal was very lame on that limb. The navel appeared to be healthy.

Result.-After treatment the foal gradually got better and finally made a complete recovery.

This was the only case on the premises during the season.

Case, No. I $2 \mathrm{I}$.

The foal was seven days old when the first symptoms were noticed and a dose of serum was given three days later. Both hocks and the left stifle were affected, causing lameness in both hind limbs; temperature ro2 ${ }^{\circ}$. The foal was very weak and had to be lifted up to suck.

Result.-Recovery. After treatment the foal gradually got better but it remained in a somewhat unthrifty condition.

This was the only case of joint-ill on the premises this season. 


\section{Case No. I 22.}

The foal was six days old when it was first seen to be ill and it was given a dose of serum on the following day. The left hock was very much enlarged and there was great lameness in that limb. The navel was suppurating.

Result.-Recovery. After treatment the foal gradually improved but it remained in an unthrifty condition. When three months old it was treated for worms and it then improved considerably.

This was the only case of joint-ill on the premises this season.

$$
\text { Case No. I23. }
$$

The foal was four days old when it was first seen to be affected and it was given a dose of serum ten days afterwards. The left stifle and elbow joints were affected and the urachus was pervious. There were no other symptoms.

Result.-After treatment the foal made good progress and finally recovered.

This was the only case of joint-ill on the premises this season.

$$
\text { Case No. I } 24 .
$$

The foal was six days old when it was first attacked and a dose of serum was given two days later and repeated after twelve days. The left stifle was the only joint affected and the navel appeared to be healthy. There were no other symptoms.

Result.-Recovery.

This was the only case of joint-ill on the premises this season.

$$
\text { Case No. } 125 \text {. }
$$

The foal was five months and fifteen days old when it was first noticed to be affected. A dose of serum was given on the following day and repeated after fourteen days. The left hip and stifle joints were affected but the navel was healthy and there were no other symptoms.

Result.-Recovery.

This was the only case of joint-ill on the premises this season.

$$
\text { Case No. } 126 .
$$

The foal was two months old when it was first treated and it was said to have been ill for about six weeks. It was given a dose of serum when first seen, and that was repeated after sixteen days. The left stifle and hip joints were affected, but the navel appeared healthy and there were no other symptoms.

Result.-Recovery. After treatment the foal made good progress except that an abscess formed on the hip and was opened at the time of the second injection. After that the foal did very well.

This was the only case of joint-ill on the premises this season.

\section{Case No. I 27.}

The foal was five days old when it was first noticed to be ill and a dose of serum was given nine days later and repeated after seven days. The left stifle was the only joint affected and there were no other symptoms, the navel being apparently healthy.

Result.-Partial recovery. After treatment the case made slow progress, and there was still an enlargement of the stifle after four months although the lameness had disappeared.

There were no other cases of joint-ill on the premises. The dam of this foal had retention of the placenta and metritis, from which she recovered after about forty-eight hours. 
Case No. 128.

The foal was twelve days old when it was first attacked and a dose of serum was given two days later and repeated after a week. The right hock and elbow joints were affected. The navel was suppurating and the urachus pervious.

Result.-No improvement, and the foal died six days after the second injection.

There was no other case on the premises during the season.

\section{Case No. 129.}

The foal was five days old when the first symptoms were noticed and it was given a dose of serum two days later. The right hock joint was swollen, but the navel was apparently healthy, and there were no other symptoms.

Result.-Recovery. After treatment the foal made good progress, and the swelling of the hock gradually subsided.

There was no other case of the disease on the premises this season.

\section{Case No. I 30.}

The foal was five weeks old when it was first seen, and it had then been showing symptoms for one day. A dose of serum was injected and repeated a week later. The right hip joint was affected, causing great lameness. The navel was suppurating and the urachus pervious.

Result.-Death about three weeks after treatment. There was no improvement after the injection of the serum.

This was the only case of joint-ill on the premises this season.

\section{Case No. I 3 I.}

The foal was twenty days old when the first symptoms were noticed and it was given a dose of serum on the following day. The right hip and left hock joints were enlarged, and the navel was suppurating and the urachus pervious.

Result.-Recovery. After the injection of serum the foal made very good progress, and it had almost completely recovered in a week.

This was the only case of joint-ill on the premises this season.

\section{Case No. $3^{2}$.}

The foal first showed symptoms when it was five days old and it was given a dose of serum six days afterwards. The left elbow joint was affected, and the navel was suppurating and the urachus pervious.

Result.-Recovery. None of the other joints became affected, and the foal made good progress.

This was the only case of joint-ill on the premises this season.

\section{Case No. I 33 .}

The foal was a week old when it was first attacked and a dose of serum was given on the following day and repeated a week later. The right knee and stifle joint were affected. The navel was suppurating and the urachus pervious.

Result.-After treatment the foal made good progress and recovered without any of the other joints becoming affected. It was reported, however, that it died from "intestinal trouble" when two months old. 


\section{Case No. I34.}

The foal was nine days old when it was first attacked and it was given a dose of serum on the following day. Both knee joints were swollen, but the navel appeared healthy and there were no other symptoms.

Result.-Recovery. After treatment the foal made good progress, the swelling of the knees subsiding after twenty-four hours.

$$
\text { Case No. } 135 \text {. }
$$

The foal was ten days old when it was first seen to be affected and it was given a dose of serum four days later. The left hip joint was the only one affected, and there was no other symptom.

Result.-Recovery. After treatment the foal made rapid progress.

This was the only case of joint-ill on the premises this season.

$$
\text { Case No. }{ }_{3} 6 \text {. }
$$

The foal was three weeks old when symptoms were first noticed and a week later a dose of serum was given and repeated after seven days. The left stifle and hock joints were affected, but the navel was apparently healthy. The foal was thought to be in a pretty hopeless condition, as it had to be raised to suck.

Result.-Death three days after the second injection.

There were no other cases of joint-ill on the premises this season.

$$
\text { Case No. } 137 \text {. }
$$

The foal was nine days old when it was first noticed to be affected and it was given a dose of serum three days later. The left hip joint was affected, and the navel was suppurating and the urachus pervious.

Result. - No improvement, and death after two days.

There were no other cases of joint-ill on the premises this season.

$$
\text { Case No. } 3^{8 .}
$$

The foal was five days old when the first symptoms were noticed and a dose of serum was given two days later. The left stifle and hock joints were affected, and the navel was suppurating and the urachus pervious. There were also symptoms of pneumonia, and the case was considered hopeless.

Result.-Death after twelve hours.

This was the only case of joint-ill on the premises this season.

\section{Case No. 139 .}

The foal was attacked when a week old and it was a fortnight later before it was given a dose of serum. The left stifle and hip joints were affected. The navel was suppurating and the urachus pervious. There were also symptoms of pneumonia, and the case was considered hopeless.

Result.-Death on the following day.

There was no other case of joint-ill on the premises during the season.

$$
\text { Case No. } 140 .
$$

The first symptoms were shown when the foal was four days old and it was given a dose of serum on the following day. The left stifle joint was slightly swollen and the urachus was pervious. The latter was dressed with an antiseptic.

Result.-Recovery. After treatment the foal made very good progress.

There was one other case of joint-ill on the premises this season. 
Case No. ${ }_{4} 4$.

The foal first showed symptoms when it was three days old and it was given a dose of serum four days later. The right hock was enlarged, but the navel appeared normal.

Result.-Recovery. After treatment the hock abscess discharged and then healed up.

This was the only foal born on the premises this season, but the previous year a foal had joint-ill on the farm and recovered.

\section{Case No. I 42 .}

The foal was a fortnight old when it was first attacked and it was given a dose of serum a week later. Both hock joints were enlarged, and the off fore leg was very much swollen. Temperature I04. The navel appeared normal, but the foal was very stiff and unable to rise without assistance.

Result.-Complete recovery. Six days after the injection of serum the foal appeared much brighter and the fore leg had become almost normal, but the left hock was still enlarged and the animal was unable to get up without assistance. It had completely recovered twelve days after the injection.

There were no other cases of the disease on the farm this season.

$$
\text { Case No. } 143 \text {. }
$$

The foal was six weeks old when it was first given a dose of serum, and it had then been showing symptoms for two days. The right knee was inflamed, causing much lameness; temperature $105^{\circ}$. The navel was apparently normal. The foal was in good condition and had previously appeared to be doing quite well.

Result.-No improvement, and death after seven days.

There was one other case of joint-ill on the premises during the season, and it also terminated fatally.

\section{Case No. 144 .}

The foal was five days old when it first showed symptoms and it was given a dose of serum on the same day. The right fore fetlock joint was affected, and the foal was unthrifty and would not suck. The navel appeared to be normal.

Result.-Recovery. After treatment the foal improved slowly, although it had to be hand-reared. All the symptoms of joint-ill had disappeared after three months.

This was the only case of joint-ill on the premises during the season.

$$
\text { Case No. } \mathrm{I} 45 \text {. }
$$

Symptoms were first shown when the foal was nine days old and a dose of serum was given the same day and repeated after ten days. The left elbow and knee joints were affected, causing great lameness. The navel appeared normal, and there were no other symptoms.

Result.-Recovery. After the first injection the foal improved rapidly, but ten days later it again became lame and it was then given a second dose, after which gradual but complete recovery took place.

There was no other case of joint-ill on the premises during the season.

$$
\text { Case No. } 146 .
$$

The foal was two days old when it was first attacked and it was given a dose of serum on the following day. The left stifle, hock, and fetlock 
joints were affected, and the foal was very lame in that leg; temperature IO $3^{\circ}$. The navel was apparently normal.

Result.-No improvement, and death after four days. After treatment the right hind leg and left fetlock also became affected.

The left stifle and hock joints were forwarded to the College, where the examination showed the presence of small bacilli which grew very meagrely a blood-agar. Their exact nature was not determined.

No other case of joint-ill had occurred on the farm during the previous ten years.

\section{Case No. 147.}

This foal was said to have been ill from birth and it was given a dose of serum when it was five days old. Both stifles were said to be in a "dropsical condition" but cold and painless; temperature $1 \circ 3^{\circ}$. The foal grunted a good deal and sucked irregularly. The navel appeared to be normal.

Result. - Death two days after the injection.

It was reported that the post-mortem examination showed "signs of peritonitis."

On the same farm two other foals were born during the season, and each of them only lived for a few hours.

\section{Case No. 148 .}

The foal was seventeen days old when it was first attacked and a dose of serum was given four days later and repeated after eight days. The right elbow was the only joint affected; the foal was very lame in that limb but quite lively, and the navel was apparently normal.

Result.-Partial recovery. After treatment the left stifle joint was attacked and the second dose of serum was then given. Twenty days later the elbow joint became normal, but the stifle was still much enlarged and the foal was lame in that limb. When seen three months later there was still slight swelling of the stifle.

This was the only case of joint-ill on the premises during the season.

\section{Case No. $\mathrm{I} 49$.}

The foal was six days old when it was first noticed to be ill and a dose of serum was then given and repeated after eight days. The left hind fetlock and right stifle joints were affected, and the foal was very lame in these limbs but able to suck well. The navel was suppurating but the urachus was closed.

Result.-Recovery. After the first injection the left hind fetlock improved, but the swelling of the right stifle joint increased and had extended down to the hock joint when the second injection was given. This swelling afterwards burst, and the foal made a complete recovery.

This was the only case of joint-ill on the premises during the season.

$$
\text { Case No. I } 50 .
$$

The foal was two months old when it was first seen and it had then been showing symptoms for about a week. A dose of serum was given and repeated eleven days later. The left stifle and right hind fetlock joints were affected, and the foal was in an unthrifty condition. The navel appeared to be normal.

Result.-Partial recovery. At the time of the second injection the lameness had decreased, and the swelling of the fetlock joint had almost entirely disappeared, but the stifle was still enlarged. When seen three 
months later there was no lameness, but the stifle was still enlarged. The foal had thriven well.

There was one other case of joint-ill on the premises earlier in the season, and it terminated fatally after about a week's illness.

\section{Case No. ${ }_{5} \mathrm{I}$.}

The foal was three months old when it was given a dose of serum and it had been showing symptoms for four days. The left shoulder was the only joint affected; temperature $105^{\circ}$. The navel appeared to be normal, and the foal was sucking well but appeared dull.

Result.-Recovery. When seen a week after the injection the foal was almost sound, and its general health was much improved. After three months it appeared quite sound.

There was no other case of joint-ill on the premises during the season, but one case in 1918 .

$$
\text { Case IVo. } 5^{2} \text {. }
$$

The foal was twenty days old when it was first seen to be ill and a dose of serum was then given and repeated after a week. The right stifle was the only joint affected. It was very much inflamed, and the temperature was I04. The navel appeared to be normal.

Result.-Death. At the time when the second dose of serum was given the foal was only slightly lame and the temperature was Ior $4^{\circ}$. A week later the foal walked quite sourd, but twenty days after the second injection it showed symptoms of pneumonia and it died two days later.

\section{Case No. 153 .}

The foal was about six weeks old when it was first seen and it had then been showing symptoms for six days. It was given a dose of serum and three other doses were afterwards given at intervals of seven days. The left hind fetlock was the only joint attacked, and the temperature was $105^{\circ}$. The foal was able to get up quite easily, and the navel appeared to be normal.

Result.-Death twenty-two days after the first dose of serum was given. A week after the foal was first treated the fetlock joint had decreased in size, but in the interval the left stifle and right hock joints had been attacked and the temperature was $\mathrm{IO}_{4}^{\circ}$. The foal had some difficulty in rising, and its condition subsequently became worse.

One mare aborted on the premises, but there was no other case of joint-ill during the season. There was one case in 1918.

\section{Case No. I54.}

The foal was thirteen days old when it was first attacked and it was given a dose of serum on the following day. Both stifle joints were enlarged, and the navel was suppurating. The temperature was normal, and the foal was in good condition.

Result.-Recovery. After treatment there was gradual improvement.

No other case of joint-ill occurred on the premises during the season.

$$
\text { Case No. I } 55 \text {. }
$$

The foal was nine days old when it was first noticed to be ill and it was given a dose of serum on the same day. The left hock was much inflamed, and the temperature was $105^{\circ}$ The navel was normal.

Result. - No improvement, and death after six days.

This was the only case of joint-ill on the premises during the season. 


\section{Case No. 156 .}

The foal was three weeks old when it was first attacked and it was given a dose of serum seven days later. The right stifle joint was much swollen, and an abscess had formed in front of the sternum. The navel was discharging.

Result.-Death. After treatment the foal appeared to improve for a time, but it died suddenly five days after the injection of serum.

There was one other case of navel-ill on the same premises during the season, and it was rapidly fatal.

\section{Case No. I 57 .}

The foal was eight days old when it was first attacked and a dose of serum was given two days later. The right knee was the only joint affected, and the navel was suppurating. The foal was in good condition.

Result.-Gradual improvement, and eventual recovery.

This was the only case of joint-ill on the premises during the season.

$$
\text { Case No. }{ }^{5} 8 .
$$

The foal was eleven days old when it was first attacked and it was given a dose of serum four days later. The right knee and left stifle joints were swollen, and the temperature was high. The navel appeared to be normal.

Result.-No improvement, and death after four days.

\section{Case No. 159.}

The foal was four days old when it was first attacked and it was given a dose of serum four days later. The right hock joint was affected, and an abscess had formed in the thigh. The navel appeared to be normal. The foal was suffering from general weakness.

Result.-No improvement, and death twenty-two days after the injection of serum.

This was the only case of joint-ill on the premises during the season.

$$
\text { Case No. } 160 .
$$

The foal was seven days old when it was first noticed to be ill and a dose of serum was given on the following day and repeated after six and eighteen days. The right hock joint was swollen and painful, the foal was dull in appearance, and the temperature was $105^{\circ}$. The navel was moist.

Result.-Recovery. The temperature did not return to normal until after the third injection, and the swelling of the hock persisted for about two months, but afterwards disappeared entirely.

This was the only case of joint-ill on the premises during the season.

Case No. $16 \mathrm{r}$.

The foal was a fortnight old when it was first attacked and a dose of serum was given seven days later and repeated after two and six days. The right shoulder and right fore fetlock joints were affected and the navel was suppurating.

Result.-Recovery. There was no improvement until after the second injection, and the right fore fetlock suppurated and burst. The shoulder remained enlarged for about six weeks, but at the end of three months the foal appeared to be normal.

There was no other case of joint-ill on the premises during the season. 
Case No. 162 .

The foal was nineteen days old when it was first noticed to be ill and it was given a dose of serum two days later. One hock was much enlarged and discharging pus and the navel was suppurating. The foal was continually lying down but it was able to suck when assisted on to its feet.

Result.-Death three days after the injection of serum.

This was the only case of the disease on the premises during the season.

$$
\text { Case No. }{ }^{16} 6 .
$$

The foal was twenty-five days old when it was first attacked and it did not receive a dose of serum until thirteen days afterwards. Both hocks wereaffected and the navel was suppurating. The temperature was high and the foal had difficulty in rising.

Result.-No improvement, and death six days after the injection of serum.

This was the only case of joint-ill on the premises during the season.

The left knee of this foal was sent to the College and examination showed. that the case was one of pure streptococcus infection.

\section{Case No. 164 .}

The foal was attacked when it was five days old and it was given a dose of serum on the same day. The left hock was affected and the foal was in a weakly condition. The navel was discharging and the urachus pervious..

Result.-No improvement, and death after fourteen days.

This was the only case of joint-ill on the premises during the season.

\section{Case No. 165 .}

The foal was twenty-four days old when it was first treated with serum, and it had been showing symptoms for six days. A second dose of serum was given seventeen days after the first. The left stifle and hip joints were affected and the foal was very lame and appeared dull. The urachus was. pervious.

Result.-No improvement, and death five days after the second injection.

This was the only case of the disease on the premises during the season.

\section{Case No. 166.}

The foal was twenty-one days old when it was given a dose of serum, and' it was reported to have been showing symptoms for "a few days." The right. stifle joint was very much swollen and the urachus was pervious.

Result.-Death after nine days. There was no improvement after theinjection of serum and abscesses formed on different parts of the body.

This was the only case of joint-ill on the premises during the season.

$$
\text { Case No. } 167 .
$$

This foal was six weeks old when it was first noticed to be ill and it was. given a dose of serum on the same day. The navel appeared to be normal, and the general appearance of the foal was stated to be that of joint-ill. Colicky symptoms were exhibited.

Result.-At first there appeared to be some improvement, but subsequently suppuration took place in connection with the left shoulder and the right hind leg, and the foal died fifty days after the injection of serum.

There was no other case of joint-ill on the premises during the season. 
Case No. 168.

The foal was twenty-six days old when it was first attacked and it was given a dose of serum three days later. Both knees were swollen, the foal was in poor condition, and the urachus was pervious.

Result.-No improvement, and death after three days.

This was the only case of joint-ill on the premises during the season.

Case No. 169.

This foal was twenty days old when it was first attacked and a dose of serum was given on the following day and repeated four days later. Both hocks were affected and the navel was moist.

Result.--Recovery. After the first injection the swelling disappeared from both hocks, but an abscess formed in the mammary region and was opened, after which the foal made a good recovery.

This was the only case of joint-ill on the premises during the season.

\section{Case No. 170.}

The foal was eleven days old when it was first attacked and a dose of serum was given three days later. Both hocks and the right shoulder joint were affected, and the foal was unable to gett up without assistance. The navel appeared to be normal.

Result.-Recovery. Distinct improvement was noticed within twenty-four hours after the injection of serum, and in three days the foal was able to get up without help. Afterwards recovery was uninterrupted.

This was the only case of joint-ill on the premises during the season.

$$
\text { Case No. I } 7 \text { I. }
$$

The foal was ten days old when it was attacked and it was given a doseof serum on the following day. The right hip and both hock joints were affected, and the foal was in a very poor, weak condition. The navel appeared to be normal.

Result. - No improvement, and death after two days.

\section{Case No. I72.}

The foal was three weeks old when it was first attacked and a dose of serum was injected twenty days afterwards and repeated after four and fifteen days. The left shoulder and stifle and right knee and hock joints were affected. The foal was very lame but in good condition and it continued to suck its dam until the last.

Result.-Death fifteen days after the last injection. After the first dose of serum there was distinct improvement, but later the right hock and left. stifle suppurated and burst. Finally the foal fell into a ditch and died from exhaustion.

This was the only case of joint-ill on the premises during the season.

$$
\text { Case No. I } 73 \text {. }
$$

The foal was attacked when it was twenty-three days old and it was given a dose of serum three days later. The left stifle and right fetlock joints were affected, and the navel was suppurating and the urachus pervious. The foal was in a very poor condition and its temperature was 106.3.

Result.- No improvement, and death about ten days after the injection.

No previous case of joint-ill had been known to occur on the premises. 


\section{Case No. 174 .}

The foal was a week old when it first showed symptoms and a dose of serum was given three days later and repeated after two days. The left stifle and hock joints were affected, causing lameness, and the foal had sometimes to be assisted on to its feet. The navel was suppurating.

Result.-General improvement set in after the second injection, and eight days later the foal was walking fairly well.

When first seen a swab was taken from the suppurating navel and sent to the College for examination. Microscopic and cultural examination showed that it contained mixed bacteria, including staphylococci, streptococci, and bacilli, some of the last being positive and others negative to Gram.

This was the only case of joint-ill on the premises during the season.

$$
\text { Case No. } 175 \text {. }
$$

The foal was attacked when six days old and a dose of serum was given on the following day and repeated after a week. The left stifle and hock joints were first affected, and later the elbow joints became involved. The foal was very lame and could not rise without assistance, but it sucked well when on its legs. The navel was suppurating and the urachus pervious.

Result.-No improvement, and death four days after the second injection.

The left elbow joint, which was stated to be the worst affected one, was forwarded to the College, and examination showed that the joint cavity contained coliform bacilli in a state of purity.

$$
\text { Case No. I } 76 \text {. }
$$

First symptoms were noticed when the foal was two days old and it was given a dose of serum two days later. The left hock and stifle and both knee joints were affected; temperature $103^{\circ}$. The navel was apparently normal.

Result.-Death on the day of injection.

The post-mortem examination showed extensive bi-lateral pleurisy and the chest cavity contained about I $5 \mathrm{oz}$. of a turbid orange-coloured exudate.

The left knee and hock, together with portions of lung, etc., were forwarded to the College for examination, which indicated that the case was one of infection with coliform bacilli.

This was the only case of joint-ill on the premises during the season.

\section{Case No. 177 .}

The foal developed symptoms two days after birth and a dose of serum was given then and repeated seven days later. The right hock and left stifle and fetlock joints were affected, and the navel was discharging.

Result.-Recovery. After treatment improvement was slow but gradual. Seventeen days after the second injection the navel had healed and after that the foal did well.

There was one other case of joint-ill on the premises (No. I8I) during the season.

$$
\text { Case No. } 7^{8} \text {. }
$$

The foal was given a dose of serum when it was three weeks old and it had been showing symptoms "for at least four days." Both hock and stifle joints were affected, and the navel was suppurating. The foal was in a very unthrifty condition.

Result.-Death fourteen days after the injection of serum. After treatment the navel healed up and the foal improved slightly at first, but its death was rather sudden. 
After death a turbid, red exudate was reported to have been found in the affected joints, but the internal organs appeared to be normal.

This was the only case of joint-ill on the premises during the season. There had been a previous case some years ago and it ended in recovery.

\section{Case No. I 79 .}

The foal was attacked when it was eleven days old and a dose of serum was given on the following day. The right hind coronet was swollen and painful. The navel was suppurating, and the temperature was I03.4.

Result.-Recovery. After treatment improvement was rapid, and the navel stopped discharging and healed in a week. A blister was applied to the affected joint five days after the injection, and thereafter recovery was uneventful.

This was the only case of the disease during the season.

Case No. 180 .

The foal was attacked when it was five weeks and three days old and it was treated with serum on the following day. The right shoulder and elbow joints were affected, causing much lameness, and the temperature was $105^{\circ} 4^{\circ}$. The navel appeared to be normal.

Result.- Recovery. After treatment the joint swelling increased in size and was opened, allowing the escape of a large quantity of clear serous fluid containing some flocculent material. Afterwards the temperature gradually came down to normal, and the wound healed without suppuration.

This was the only case of the disease on the premises during the season.

$$
\text { Case No. I } 8 \text { I. }
$$

The foal was about six weeks old when it was first given a dose of serum and it had then been showing symptoms for three days. There was a large painful swelling involving the stifle joint; temperature $104^{\circ}$. The navel appeared to be normal.

Result.-Death after three days.

On post-mortem examination an abscess was found in the right quarter, and the muscles there were necrosed and under-run with pus. The hip joint contained pus, and there were patches of erosion on the articular cartilages.

The left knee of this foal was forwarded to the College, where examination of the joint contents showed a pure streptococcus infection.

Case No. I 77 occurred on the same premises.

\section{Case No. $\mathrm{r} 82$.}

The foal was six days old when it was first attacked and serum was injected on the same day. The right shoulder was swollen and painful, and the temperature was $104^{\circ}$ in the morning and $102.6^{\circ}$ in the evening. The navel appeared to be normal.

Result.-Death after thirty-two days. The foal appeared to make a rapid recovery, and after a week it was turned out and did well until the twentysixth day. Post-mortem examination showed pneumonia and pleurisy. The shoulder joint had quite recovered.

Case No. 183 .

The foal was sixteen days old when it was first attacked and it was given a dose of serum five days afterwards. Both hocks were affected. causing 
much lameness. There was also general stiffness, and the foal was unable to rise; temperature $105^{\circ}$. The navel was swollen and the urachus pervious.

Result.-Recovery. Progress was slow and the hocks were enlarged for over two months.

This was the only case of joint-ill on the premises during the season.

\section{Case No. 184 .}

The foal was first noticed to be ill when it was a fortnight old and a dose of serum was given the same day. The right stifle and left hock and elbow joints were affected, and the navel was suppurating. The foal had a high temperature, was unable to get up without assistance, and was disinclined to suck.

Result.-Recovery. From the third day onwards the foal showed steady improvement, but the stifle remained stiff for about five weeks.

There was no other case of joint-ill during the season.

\section{Case No. 185 .}

This foal was about six weeks old when it was first treated and it was. said to have been ill for about five weeks. A dose of serum was then given, and it was repeated on the third, tenth, and fifteenth days afterwards. The knee and hock joints were affected, causing much lameness, and the temperature was slightly above normal. The navel was "almost normal" in appearance.

Result.-Recovery. The swelling of the joints and the lameness gradually disappeared.

Cases of joint-ill had occurred on the farm for several years.

\section{Case No. I 86.}

The foal was thirty-six days old when it was first seen and it had then been showing symptoms for about five days. A dose of serum was given, and it was repeated on the third, tenth, and twenty-first days afterwards. One of the hock joints was enlarged and the foal was very lame on that leg. The navel was apparently normal.

Result.- Recovery. On the third day after the first injection of serum the foal appeared to be much worse, but after that it made a good recovery.

There had been another case of the disease on the place earlier in the season and it had ended fatally.

\section{Case No. 187 .}

This foal was a week old when the first symptoms were noticed, and a dose of serum was given a week later. The hock and shoulder joints were affected, and the navel was suppurating.

Result.-No progress, and death after five days.

Case $25^{2}$ was born in the same yard on the same day.

Case No. 188.

The foal was ten days old when it was first attacked and it was given a dose of serum four days later. The left knee was affected, the navel was suppurating, and the foal refused to suck.

Result.-Recovery, which was complete in about ten days.

There was no other case of joint-ill during the season.

$$
\text { Case No. } 189 \text {. }
$$

The foal was first seen to be ill when it was three days old and it was given a dose of serum on the following day. The right stifle joint was the 
only one affected and it was only slightly swollen, but the foal was lame in that leg. The navel was suppurating.

Result.-Recovery. The navel had healed up completely in about a week after the injection, and the lameness gradually decreased.

This was the only case during the season.

\section{Case No. rgo.}

The foal was sixteen days old when it was first noticed to be ill and a dose of serum was given five days later and repeated after nine days. The left knee and stifle joints were affected. The navel was suppurating and the urachus pervious.

Result.-Death thirteen days after the second injection. Three days after the second injection a large abscess developed in the left hind leg between the stifle and hock joints, and the foal became gradually weaker. The navel healed slowly but there was no improvement in the affected joints.

This was the only case of joint-ill during the season.

\section{Case No. I9I.}

The foal was seven days old when it was first noticed to be ill and it was given a dose of serum on the following day. The left stifle and hock joints were affected, and the foal was dull, had lost appetite, and was unable to get up without assistance. The navel was suppurating.

Result.-No improvement, and death after five days.

This was the only case during the season.

Case No. I92.

The foal was twenty-five days old when the first symptoms were noticed and it was given a dose of serum four days later. Both hocks were affected, the navel was moist, and the foal was in a low condition.

Result.-Death three or four days after the injection.

This was the only case during the season.

\section{Case No. I93.}

The foal was six days old when it was attacked and it was given a dose of serum eight days later. The navel was suppurating and "nearly all the joints were affected." The foal was considered to be in an almost hopeless condition.

Result.-Death (exact date not reported).

This was the only case of joint-ill during the season.

\section{Case No. 194.}

The foal was twenty-three days old when it was first given a dose of serum and it had then been showing symptoms for nine days. Both hocks. were affected, and one of them had suppurated and was opened. The navel appeared to be normal.

Result.-Death three or four days after injection.

There had been no other case of joint-ill during the season.

\section{Case No. 195 .}

The foal was attacked when it was eighteen days old and a dose of serum was given on the following day. The right hip was affected but the navel appeared to be normal.

Result.-No improvement, and death after seven days.

This was the only case of joint-ill on the premises during the season. 
Case No. 966.

The foal was two days old when it was first noticed to be ill and it was given a dose of serum three days later. The right stifle and thigh were swollen and discharging freely. The navel was suppurating and the urachus pervious.

Result.-No progress, and death after seven days.

This was the only case of joint-ill on the premises during the season.

\section{Case No. 197 .}

The foal was three days old when the first symptoms were noticed and a dose of serum was given four days later. The left stifle and hock joints were affected, and the foal was very lame in that limb and in a weak condition. The navel was suppurating.

Result.-No improvement, and death after four days.

This was the only case of the disease on the premises this season.

\section{Case No. 198.}

This foal was given a dose of serum on the day of birth and it developed symptoms of joint-ill when it was nineteen days old. A second dose of serum was given five days later, and a third after eleven days. When first treated one hock joint was affected, there was a slight discharge from the navel, and the urachus was pervious. The foal was constipated.

Result.-No improvement, and death nineteen days after the third injection.

A sample of pus from an abscess which had developed on the foal at the time of the second injection of serum was forwarded to the College for examination and was tound to be very rich in streptococci, which were cultivated in purity from it. After the foal's death the right hind fetlock joint was also forwarded for examination, and smears made from the joint contents showed streptococci, apparently in a state of purity. The organisms were present in all forms from diplococci up to long chains which extended across the whole field of the microscope and comprised over 200 elements. Tubes inoculated in series with material from the joints yielded abundant streptococcus colonies, pure except in the first tube of the series, in which there were six colonies of the staphylococcus pyogenes aureus.

This was the only case of joint-ill on the premises during the season, but four other foals born during the season were injected on the day of birth with serum.

\section{Case No. I99.}

The foal was twenty-six days old when it was first attacked and it was given a dose of serum eight days later. The left hind leg in the region of the hip and stifle was swollen but not suppurating; the foal was stiff in all its limbs and moved with difficulty. The temperature was elevated. The navel was apparently normal.

Result.- No improvement, and death after seven days.

This was the only case of joint-ill on the premises this season.

Case No. 200.

The foal was four days old when the first symptoms were noticed and it was given a dose of serum three days later. The hock and stifle joints were affected, the temperature was high, and the navel was suppurating.

Result.-No improvement, and death after four days.

This was the only case of the disease on the premises during the season, but the same mare's foal died from joint-ill in $19 \mathrm{r} 8$. 
Case No. $20 \mathrm{I}$.

The foal was first noticed to be ill when it was four days old and a dose of serum was injected the same day. The right hock and fetlock joints were very much swollen, the temperature was $103^{\circ}$, and the navel was swollen and discharging. The foal was rather dull, but able to suck well.

Result.-Recovery. Two days after the injection the navel appeared to be drying up, but the swelling of the joints persisted for several weeks and then gradually disappeared.

This was the only case of the disease on the premises during the season.

Case No. 202.

The foal was attacked on the second day after birth and it was given a dose of serum on the following day. The left stifle was much swollen and fluctuating, and the foal was very lame on that limb. The navel was swollen and suppurating.

Result.-Recovery.

This was the only case of the disease on the premises this season.

$$
\text { Case No. } 203 .
$$

The foal appeared to be infected at birth and a dose of serum was given when it was two days old. One stifle joint was very much swollen, and the foal had a high temperature and was unable to stand. The navel appeared to be normal

Result.--Death on the day following the injection of serum.

This was the only case of joint-ill on the premises during the season.

$$
\text { Case No. } 204 .
$$

The foal was one month old when it was given a dose of serum and it had then been showing symptoms for nine days. The left hock was swollen, causing acute lameness. The urachus was pervious, and the foal had an unthrifty appearance.

Result.-Death. When seen a week after the injection of serum the lameness had disappeared, and the foal appeared to be doing well except that the swelling of the hock remained. It died some weeks later.

This was the only case of joint-ill on the premises this season.

$$
\text { Case No. } 205 .
$$

The foal was nineteen days old when the first symptoms were noticed and it was given a dose of serum two days later. Both hocks were affected and the temperature was $104^{\circ}$. The urachus was pervious and the foal was unable to rise.

Result.-Death on the day following the injection of serum.

$$
\text { Case No. } 206 .
$$

The foal was about six weeks old when it was first attacked and it was given a dose of serum five days later. The left stifle joint was affected and a large abscess had developed in the ischial region. The navel appeared to be normal.

Result.-Death (date not stated). No progress was noted after treatment. This was the only case of the disease on the premises during the season.

$$
\text { Case No. } 207 \text {. }
$$

This foal was said to have shown symptoms on the day of birth and a dose of serum was given when it was two days old and repeated after fifty 
days. The hip and stifle joints on one side were swollen and painful, and the temperature was $106^{\circ}$. The navel appeared to be normal.

Result.-Recovery. Eight days after the first injection the foal was found to have improved considerably, the temperature was then $103^{\circ}$, there was no lameness, and the swelling of the joints had disappeared. Fifty days afterwards the foal had a relapse (symptoms not stated), and it was then given another dose of serum. A week later it was found to have recovered.

This was the only case of joint-ill during the season, but three previous foals out of the same mare had died from navel-ill.

Case No. 208.

The foal was five weeks old when it was given a dose of serum and symptoms had appeared on the previous day. The right hip joint was much swollen and the foal was very lame; temperature $105^{\circ}$ The navel was apparently normal.

Result.-Death after fourteen days. There was no improvement after the injection of the serum.

This was the only case of the disease on the premises during the season.

Case No. 209 .

The foal was five weeks old when it was first treated and it had then been showing symptoms for three days. One hock joint was affected and the temperature was $105^{\circ}$. The navel appeared to be normal.

Result.-Death after five days. No improvement occurred after the injection of the serum.

This was the only case of the disease on the premises during the season.

\section{Case No. 2 го.}

The foal was attacked when it was two days old and it was given a dose of serum the same day. Both shoulders were affected and the temperature was I05. The navel was apparently normal.

Result.-Recovery within a week after treatment.

This was the only case of the disease on the premises this season.

$$
\text { Case No. } 2 \mathrm{I} \mathrm{I} \text {. }
$$

The foal was attacked when four days old and it was given a dose of serum four days later. Both hock joints were affected and the foal was unable to rise; temperature $104^{\circ}$. The navel appeared to be normal.

Result.-No improvement was noted after the injection of serum and the foal died about nine weeks later.

There was one other case of joint-ill on the farm in I9I9, and the foal out of the same mare developed the disease in $19 \times 7$. Both of these recovered.

\section{Case No. $2 \mathrm{I} 2$.}

The foal was attacked when nine days old and treated with serum on the following day. It was very lame in the near hind leg, but the seat of disease could not be located ; the urachus was pervious and the temperature was $105^{\circ}$.

Result.-Recovery (date not stated).

\section{Case No. 213.}

The foal was attacked when five days old and it was given a dose of serum on the following day. The left stifle and elbow joints were affected, the 
temperature was $105^{\circ}$, and the foal was unable to stand. The navel was apparently normal.

Result.-No improvement, and death after twenty-eight days.

This was the only case of joint-ill on the premises this season.

Case No. 214.

The foal was nineteen days old when it was first attacked and it was given a dose of serum four days later. The knee and hock joints on both sides were affected, but the navel was apparently normal.

Result.-Death after two days. No improvement followed the injection of the serum.

This was the only case of joint-ill on the premises this season.

$$
\text { Case No. } 215 .
$$

The foal was seventeen days old when it was first noticed to be ill and a dose of serum was given four days later. A second dose was given seven days later. Both hock joints were affected, causing much lameness, and the temperature was $105^{\circ}$ The urachus was pervious.

Result.-Recovery.

This was the only case of joint-ill on the premises this season.

Case No. 216.

The foal was fourteen days old when it was first attacked and it was given a dose of serum two days later. The left hock was affected and the foal was lame on that limb. The temperature was $1045^{\circ}$ and the urachus was pervious.

Result.-Recovery.

$$
\text { Case No. } 217 .
$$

The foal was thirteen days old when the first symptoms were noticed and it was given a dose of serum on the following day. A second dose was given thirty-seven days later. Both knees were affected and the foal was unable to rise; temperature $102^{\circ}$. The navel appeared to be normal.

Result.-Before the second injection the disease had extended to the hock and stifle joints, but eventually the foal recovered.

$$
\text { Case No. } 218 .
$$

In this case one of the hocks was said to have been enlarged at the time of birth and a dose of serum was given when the foal was nine days old. The urachus was then pervious and the temperature was $103^{\circ}$.

Result.-Recovery.

This was the only case of the disease on the premises this season.

$$
\text { Case No. } 2 \text { ×9. }
$$

The foal was four days old when it was first attacked and it was given a dose of serum on the following day. The left stifle was the only joint affected and the temperature was $102^{\circ}$. The navel was apparently normal.

Result.-Recovery.

This was the only case of the disease on the premises this season.

$$
\text { Case No. } 220 \text {. }
$$

The foal was eleven days old when the symptoms were first noticed and it was given a dose of serum three days later. The left stifle joint was affected and the temperature was $103^{\circ}$. The navel was apparently normal.

Result.-Recovery. 


\section{Case No. $22 \mathrm{I}$.}

The foal was one month old when it was given a dose of serum and it was first noticed to be ill on the previous day. The left hock was the only joint affected and the temperature was $106^{\circ}$. The navel was apparently normal.

Result.-Complete recovery.

This was the only case of the disease on the premises during the season.

\section{Case No. 222.}

The foal was two and a half months old when it was first noticed to be ill and it was given a dose of serum on the following day. The left stifle and hock joints were affected and the foal was very lame; temperature $105^{\circ}$. The navel was apparently normal.

Result.-The foal died suddenly "a few days" after treatment.

This was the only case during the season, but one foal died of joint-ill in I9I 8 .

$$
\text { Case No. } 223 .
$$

The foal was twenty-two days old when the first symptoms were noticed and it was given a dose of serum thirteen days later. The right hock and left stifle joints were affected, and the foal had been unable to rise for several days; temperature $\mathrm{IO}_{4}^{\circ}$. The navel was swollen and suppurating.

Result.-No improvement occurred, and the foal was destroyed (date not stated).

This was the only case of the disease on the premises this season.

\section{Case No. 224.}

The foal was twenty-four days old when it was first attacked and thirty days afterwards it was given a dose of serum. The left stifle and right hock joints were affected, the temperature was $105^{\circ}$, and the urachus was pervious. The foal was unable to stand and refused to suck.

Result.-No improvement, and death after four days.

This was the only case of the disease on the premises this season.

$$
\text { Case No. } 225 \text {. }
$$

The foal was attacked when it was two days old and a dose of serum was given the same day and repeated after a week. One stifle joint was affected and the navel was suppurating. The foal was in good condition and showed no other symptoms.

Result.-There was no appreciable improvement, and the foal died about three weeks after treatment was begun.

This was the only case of joint-ill on the premises this season.

\section{Case No. 226.}

The foal was attacked when it was eight days old and it was treated with serum the following day. One shoulder joint was affected, the urachus was pervious, and the foal was in rather poor condition.

Result.-Death after four days. After the injection of the serum one of the stifle joints was also attacked.

This was the only case of the disease on the premises this season.

$$
\text { Case No. } 227 .
$$

The foal was first noticed to be ill when it was two days old and a dose of serum was then injected and repeated twenty-two days later. Both hock joints were affected but the navel was apparently normal. 
Result.-Satisfactory progress, ending in recovery.

No other cases occurred on the farm during the season but joint-ill was said to have been prevalent on it in previous years.

\section{Case No. 228.}

The foal first showed symptoms when it was four days old and a dose of serum was then given and repeated ten days later. The right stifle and left shoulder joints were affected. The navel appeared to be normal.

Result.-Gradual improvement and ultimate good recovery.

This was the only case during the season, but two foals subsequently born were given a dose of serum immediately after birth.

\section{Case No. 229.}

The foal was attacked when two days old and it was given a dose of serum two days later. Both hock joints were affected and the urachus was. pervious.

Result.-Recovery. After the injection the right hock burst and discharged pus, but subsequently there was slow improvement ending in a good recovery.

This was the only case of joint-ill on the premises this season.

\section{Case No. $23^{\circ}$.}

The foal first showed symptoms when it was ten days old and it was given a dose of serum on the following day. The right stifle and hock joints were affected, the temperature was $\mathrm{IO}^{\circ}$, and the urachus was pervious. The foal was unable to rise and sucked irregularly.

Result.-Recovery. Twenty days after the injection the foal was walking sound, and the swelling had almost entirely disappeared from the hock; eventually it disappeared altogether.

No other case of joint-ill had occurred on the farm during the last seventeen years.

$$
\text { Case No. } 23^{\mathrm{I}} \text {. }
$$

The foal was first noticed to be ill when it was six days old and a dose of serum was given four days later and repeated after five days. The left stifle joint was affected, causing lameness, and the temperature was $105^{\circ} 4^{\circ}$. The urachus was pervious.

Result.-The foal made good progress and the temperature had fallen to normal six days after the second injection. At the time of the second injection an abscess, which had formed in the interval, was opened and irrigated daily for six days, after which the foal "became nearly sound."

This was the first case of joint-ill that had occurred on the premises.

\section{Case No. 232 .}

This foal was twelve days old when the first symptoms were noticed and a dose of serum was given two days later. Subsequently two other doses were given (dates not reported). Both stifles were affected but the navel appeared to be normal.

Result.-No improvement, and death about three weeks after the first injection of serum. Before death the right knee and elbow had also been attacked.

This was the only case of the disease on the premises. 


\section{Case No. 233 .}

The first symptoms were noticed on the third day after birth and a dose of serum was given the same day. Both stifles were affected and the navel was moist.

Result.-Death two days after treatment.

This was the only case of the disease on the premises during the season.

$$
\text { Case No. } 234 .
$$

The foal was six days old when the first symptoms were noticed and it was given a dose of serum eight days later. The right shoulder and elbow jo.nts were affected and the navel was suppurating. The cord was dressed and ligatured.

Result. - Death after about fifteen days. For a few days the foal seemed to impr sve, but afterwards it gradually pined away.

This was the only case of the disease on the premises during the season.

$$
\text { Case No. } 235 \text {. }
$$

The foal was five days old when the first symptoms were noticed and it was given a dose of serum on the following day. Both shoulders appeared to be affected, and the navel was wet but not swollen or suppurating.

Result.-Death on the following, day. The foal appeared to be affected with pneumonia, and the highest temperature recorded was $104^{\circ}$.

This was the only case of the disease on the premises during the season.

$$
\text { Case No. } 236 .
$$

The foal was three days old when it was first noticed to be ill and a dose of serum was given on the following day and repeated eight days later. Both knee joints were affected and the navel was moist.

Result.-Recovery. Progress was slow at first and suppuration of the navel occurred eight days after the first injection of serum. Afterwards progress was rapid.

One mare on the same farm aborted twelve weeks after service. There was no other case of joint-ill during the season, but one foal was attacked in 1918 and recovered.

$$
\text { Case No. } 237 \text {. }
$$

This foal was about eight weeks old when the first symptoms were noticed and it was given a dose of serum six days later. The off hip was the only joint affected and the navel appeared to be normal. The muscles along the back on the right side were swollen.

Result.--Recovery. After treatment an abscess formed on the right hip and burst spontaneously.

The mare had previously had five foals, three of which had navel-ill or joint-ill but only one died.

\section{Case No. 238.}

This foal was nine weeks old when it was first noticed to be ill and it was given a dose of serum two days later. An abscess had formed in front of one elbow joint and there was a swelling over the last rib on the right side.

When the foal was a week old it was noticed that urine was passing at the navel, but this ceased in about a week.

Result.-Death about eight weeks after the injection of serum.

The post-mortem showed a quantity of amber-coloured fluid in the joints.

This was the only case on the farm during the season. 


\section{Case No. 239.}

This foal was twelve days old when it was attacked and it was given a dose of serum two days later. The near stifle was the only joint affected. The navel was slightly swollen.

Result.-Recovery. Improvement began after three days and recovery was complete in about a fortnight.

This was the only foal born on the farm during the season.

$$
\text { Case No. } 240 .
$$

The foal was thirty-seven days old when it was given a dose of serum and the first symptoms were noticed eight days previously. 'The right hip joint was swollen, but the navel appeared to be normal.

Result.-Death four days after treatment. In the interval an abscess had formed in connection with the off hip and it was opened.

The near hock joint of this foal was forwarded to the College and examination showed a pure streptococcus infection.

\section{Case No. $24 \mathrm{r}$.}

This foal was three days old when the first symptoms were noticed and a dose of serum was given three days later. The only symptom reported was lameness (joint not stated), and the foal was said to be in a hopeless condition.

Result.-Death. The exact date was not reported, but the foal's left hock was forwarded and received at the College five days after the injection of serum. Examination of the joint contents proved that the case was one of streptococcus infection.

$$
\text { Case No. } 242 .
$$

This foal was weakly at birth and it was given a dose of serum as a prophylactic twelve hours afterwards. When the foal was eleven days old the right hock was attacked and a second dose of serum was given two days later. At that time the hock had burst.

Result.-Death five days after the injection of the second dose of serum.

The foal's right hock joint was forwarded to the College, and examination showed a streptococcus infection.

This was the only case of the disease on the premises during the season.

$$
\text { Case No. } 243 \text {. }
$$

This foal was four days old when the first symptoms were noticed and it was given a dose of serum the same day. The left knee and both hocks were affected. The navel had been dressed immediately after birth.

Result.-Death after three days.

The foal's left hock was forwarded to the College and examination of smear preparations showed abundant diplococci with a small number of coliform Gram-negative bacilli.

\section{Case No. 244 .}

This foal was seven weeks old when it was first attacked and a dose of serum was given two days later and repeated after five weeks. One hock joint was affected and the navel was suppurating.

Result.-Recovery. After treatment two large abscesses formed in the lumbar region. They were opened and treated antiseptically. The hock joint burst spontaneously. Three months afterwards the foal was reported to be well.

This was the only case of the disease on the premises during the season. 
Case No. 245 .

The foal was two months old when it was first reported to be ill and it was given a dose of serum on the following day. The stifle and hock of one limb were affected. The navel was slightly enlarged but not suppurating. It was thought probable that it had been affected soon after birth and had healed.

Result.-Incomplete recovery. Three months afterwards the foal was still lame, sometimes better and sometimes worse, and it was stiff in its fore fetlocks.

This was the only foal bred on the premises during the season.

Case No. 246.

The foal was ten weeks old when it first showed symptoms and it was given a dose of serum the same day. A second dose was given twenty-seven days later. The stifle was very much swollen and the temperature was $106^{\circ}$. The navel was normal.

Result. - Death twenty-five days after the injection of the second dose of serum. In the interval between the two injections the temperature fluctuated between $102^{\circ}$ and $103^{\circ}$. After the second dose of serum the lameness disappeảed and the foal seemed better for a time.

The post-mortem examination showed consolidation of the anterior portions of the lungs and there was about a quart of liquid in the thoracic cavity. The navel and all the joints then seemed normal.

This was the only case of the disease on the premises during the season.

Case No. 247.

The first symptoms were noticed when the foal was eleven days old and it was given a dose of serum three days later. The near stifle was the only joint affected and the navel was normal.

Result.-Complete recovery.

This was the only case on the premises during the season.

$$
\text { Case No. } 248 .
$$

This foal was six days old when the first symptoms were noticed and it was given a dose of serum on the following day. The off hock was then affected and the navel was pervious.

Result.-The left hock and stifle became affected, but the foal made a good recovery after about three months. In the interval it had had an attack of broncho-pneumonia.

No other case of the disease occurred on the premises this season.

\section{Case No. 249.}

The foal was eleven days old when it was first seen to be affected and a dose of serum was given on the following day and repeated after a week. A hock joint was the only one affected at the time of treatment and the navel was normal.

Result.-Death three days after the second dose of serum. Two days after the first injection the foal appeared to be a little better, but subsequently other joints became affected.

This was the only case of the disease on the premises this season.

$$
\text { Case No. } 250 .
$$

The foal was thirteen days old when it was first noticed to be ill and it was given a dose of serum on the following day. The hock and stifle joints were affected, the navel was suppurating, and the urachus was pervious. The foal had a high temperature and was weak. 
Result.-Death ten days after the injection of serum. At first there was marked improvement, but on the seventh day an abscess formed in the groin and the hip joint became enormously swollen.

This was the only case of joint-ill on the premises this season.

Case No. $25 \mathrm{I}$.

This foal was nineteen days old when it was first attacked and a dose of serum was given two days later and repeated after three days. The near hock and knee joints were affected but the navel was normal.

Result.-Incomplete recovery. The case made no progress for about ten weeks, but improvement then began, and after other six weeks it was reported that the foal looked like making a complete recovery.

This foal and its dam had before the attack been treated strictly according to the directions with serum supplied by the Clydesdale Horse Society.

There was no other case of joint-ill on the premises this season.

\section{Case No. 252.}

This foal first showed symptoms when it was a week old and it was given a dose of serum a week later. A second dose of serum was afterwards given (date not stated). Both hocks and fore fetlocks were affected and the navel was suppurating.

Result.--Recovery after two months.

Foal No. 187 was born in the same yard and on the same day, and cases of joint-ill were said to occur on the farm every year.

\section{Case No. 253 .}

This foal was twenty-four days old when the first symptoms were noticed, and it was given a dose of serum on the following day. The navel was discharging and the hocks and knees were affected.

Result.-No improvement, and death after six days.

Both hocks and other parts of this foal were forwarded to the College, where examination showed that the case was one of streptococcus infection.

This was the only case of the disease on the premises this season.

\section{LOUPING-ILL: DURATION OF THE INFECTIVITY OF THE TICKS.}

By Sir S. Stockman, Board of Agriculture, London.

IN two former papers in this Journal (Vols. XXIX. and XXXI.) the question of the duration of infectivity of ticks was discussed. The question is one of practical importance as regards measures of eradication, since an easy method of purifying pastures would be available if it were established that ticks soon lose their infectivity. All that would be necessary would be to keep sheep off the pastures until the infecting agent had disappeared from the bodies of the ticks, which, as pointed out before, may remain alive though unfed for a year or more. It had been demonstrated (see first paper, Vol. XXIX.) before the work which led up to the tick being established as the carrier of infection (see second paper, Vol. XXXI.) 